\title{
Combined walking exercise and alkali therapy in patients with CKD4-5 regulates intramuscular free amino acid pools and ubiquitin E3 ligase expression
}

Emma L Watson ${ }^{1}$, PhD; George C Kosmadakis ${ }^{2}$, Dipl Med; Alice C Smith ${ }^{1,2}$, PhD; Joao L Viana $^{3,4}, \mathrm{PhD}$; Jeremy R. Brown ${ }^{2}, \mathrm{MSc}$; Karen Molyneux ${ }^{1,2}, \mathrm{PhD}$; Izabella ZA Pawluczyk ${ }^{1}$, PhD; Michael Mulheran ${ }^{5}, \mathrm{PhD}$; Nicolette C Bishop ${ }^{3}, \mathrm{PhD}$; Susan Shirreffs ${ }^{3}, \mathrm{PhD}$; Ronald J Maughan $^{3}, \mathrm{PhD}$; Paul J Owen ${ }^{6}, \mathrm{MD}$; Stephen G John ${ }^{6}, \mathrm{MD}$; Christopher W Mclntyre ${ }^{6}, \mathrm{MD}$; John Feehally ${ }^{1,2}$ DM; and Alan Bevington ${ }^{1}$, DPhil.

${ }^{1}$ Department of Infection, Immunity and Inflammation, University of Leicester; ${ }^{2}$ John Walls Renal Unit, University Hospitals of Leicester NHS Trust; ${ }^{3}$ School of Sport, Exercise and Health Sciences, Loughborough University; ${ }^{4}$ Research Centre in Sports, Health Sciences and Human Development (CIDESD), Higher Education Institute of Maia (ISMAI), Portugal; ${ }^{5}$ Department of Medical and Social Care Education, University of Leicester; ${ }^{6}$ School of Graduate Entry Medicine and Health, University of Nottingham, Derby, UK

Corresponding author

Dr Alan Bevington

Department of Infection, Immunity and Inflammation

Maurice Shock Medical Sciences Building

University of Leicester

Leicester

LE1 9HN

United Kingdom

Tel: (+44-116) 2231402

Fax: (+44-116) 2525030

Email: ab74@leicester.ac.uk

Running Headline: Exercise and amino acids in CKD

Word Count: 4692 


\section{Abstract}

Muscle-wasting in chronic kidney disease (CKD) arises from several factors including sedentary behaviour and metabolic acidosis. Exercise is potentially beneficial but might worsen acidosis through exercise-induced lactic acidosis.

We studied the chronic effects of exercise in CKD Stage 4-5 patients (brisk walking, 30 min, 5 times/week), and non-exercising controls; each group receiving standard oral bicarbonate (STD), or additional bicarbonate (XS) (Total $n=26$; Exercising + STD $n=9$; Exercising $+X S$ $\mathrm{n}=6$; Control $+\operatorname{STD} \mathrm{n}=8$; Control $+\mathrm{XS} \mathrm{n}=3$ ). Blood and vastus lateralis biopsies were drawn at baseline and 6 months.

The rise in blood lactate in submaximal treadmill tests was suppressed in the Exercising + XS group. After 6 months, intramuscular free amino acids (including the branched chain amino acids) in the Exercising + STD group showed a striking chronic depletion. This did not occur in the Exercising + XS group. The effect in Exercising + XS patients was accompanied by reduced transcription of ubiquitin E3-ligase MuRF1 which activates proteolysis via the ubiquitin-proteasome pathway. Other anabolic indicators (Akt activation and suppression of the $14 \mathrm{kDa}$ actin catabolic marker) were unaffected in Exercising $+\mathrm{XS}$ patients. Possibly because of this, overall suppression of myofibrillar proteolysis (3-methyl histidine output) was not observed.

It is suggested that alkali effects in exercisers arose by countering exercise-induced acidosis. Whether further anabolic effects are attainable on combining alkali with enhanced exercise (e.g. resistance exercise) merits further investigation.

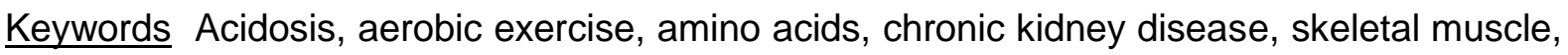
ubiquitin-proteasome pathway 


\section{Introduction}

Patients with Chronic Kidney Disease (CKD) have poor physical functioning and low exercise capacity (Johansen. 2007; Painter. 2005) arising from inactivity (Tawney et al. 2003), muscle-wasting and reduced muscle function (Diesel et al. 1990), inflammation (Kaizu et al. 2003) and anaemia (Painter and Moore. 1994). The overall effect is a downward spiral of physical inactivity and deconditioning associated with increased cardiovascular risk (Kosmadakis et al. 2011).

There is growing evidence that exercise provides benefits to haemodialysis patients, improving exercise capacity (Kouidi et al. 2004; Painter et al. 2002), cardiac risk factors (Goldberg et al. 1986), insulin sensitivity (Goldberg et al. 1983; Goldberg et al. 1986), quality of life and depression (Painter et al. 2000). However, there has been relatively little research on the pre-dialysis population. Benefits for pre-dialysis patients are potentially significant in view of the large patient numbers and prospect of earlier intervention to prevent e.g. cardiovascular disease. For such exercise to be practical and sustainable, it should be sufficiently straightforward to be performed at home without specialised training or equipment. Walking satisfies these requirements. We have recently reported a controlled study of 6-months home walking exercise in pre-dialysis CKD patients stage 4-5 (Kosmadakis et al. 2011). This demonstrated improved exercise tolerance and quality of life, reduced frequency and severity of uraemic symptoms, protection from deteriorating cardiovascular reactivity, and improved blood pressure control (Kosmadakis et al. 2011).

Metabolic acidosis is common in CKD (Kovacic et al. 2003) and a major cause of musclewasting (Mitch. 2006). Alkali therapy (sodium bicarbonate) is commonly used to correct acidosis, and in dialysis patients is associated with improved nitrogen balance (Reaich et al. 1993) increased body weight, and decreased morbidity (Stein et al. 1997; Szeto et al. 2003) and reduced protein catabolism (Movilli et al. 2009). There is evidence that muscle catabolism is also slowed by strength plus endurance training in dialysis patients (Workeneh 
et al. 2006), but this does not result in marked gains in lean body mass (LBM) at whole body level (Cheema et al. 2007a; Johansen et al. 2006; Kopple et al. 2007). The reason for this failure to increase LBM is unknown, but exercise-induced lactic acid generation in nondialysed patients might result in transient worsening of acidosis, thereby off-setting benefits from exercise. It might be possible to neutralise this acid through alkali administration. For that reason, in our recent walking study, the effect of minimising acidosis by applying additional alkali was tested in half the subjects (Kosmadakis et al. 2011).

Uraemic metabolic acidosis depletes free amino acids in skeletal muscle of dialysis patients (Bergstrom et al. 1990) and is reversed by alkali (Lofberg et al. 1997). Furthermore both in vitro (Franch et al. 2004) and in vivo (Bailey et al. 2006) metabolic acidosis impairs insulin sensitivity and protein anabolic signals through IRS-1/PI3K/Akt signalling (Bailey et al. 2006), resulting in up-regulation of the ubiquitin-proteasome pathway (UPP). Activation of the PI3K/Akt pathway suppresses expression of two ubiquitin E3-ligases found in skeletal muscle: MAFbx and MuRF-1, via an increased phosphorylation of FOXO transcription factors by Akt (Stitt et al. 2004). Consequently expression of these genes has been used as a marker of proteolysis through the UPP. Caspase- 3 cleaves actomyosin into fragments which can be degraded by the proteasome (Du et al. 2004) leaving a characteristic $14 \mathrm{kDa}$ Actin fragment which has been proposed as a muscle proteolysis marker (Workeneh et al. 2006). There is evidence in haemodialysis patients that exercise suppresses this fragment (Workeneh et al. 2006) implying decreased muscle proteolysis, but data from pre-dialysis patients is lacking.

In this study we report effects of walking exercise and alkali on these muscle biochemical parameters in patients in our earlier study (Kosmadakis et al. 2011) who consented to give skeletal muscle biopsies. The study tested the hypothesis that walking and alkali combined impose benefits on intracellular amino acid profiles and signals controlling protein catabolism which would be unobtainable with exercise or alkali alone. 


\section{Subjects and Concise Methods}

\section{Study design}

The design of this study has been described previously (Kosmadakis et al. 2011). Briefly, 40 patients with chronic kidney disease stage 4 or 5 not receiving renal replacement therapy (23 males, 17 females median age 58, range 20-83 years) were recruited, of these 40,32 patients completed the study. Exclusion criteria were age $<18$ years, pregnancy, and orthopaedic or cardiovascular disability severely limiting exercise capacity.

The first 20 patients recruited were assigned to the intervention group and exercised for 6 months as described below. Twenty other patients continued with normal physical activity (non-exercise controls). In addition, the forty patients were randomly allocated to receive additional oral bicarbonate supplementation (target plasma bicarbonate $29 \mathrm{mmol} / \mathrm{l} ; 10$ exercisers, 10 controls), or to continue with usual bicarbonate therapy (target plasma bicarbonate $24 \mathrm{mmol} / \mathrm{l} ; 10$ exercisers, 10 controls). Patients otherwise continued under usual clinical care.

\section{Participants}

Patients whose biopsy data are presented are a sub-group of those described previously (Kosmadakis et al. 2011) who consented to giving a biopsy. Patient characteristics are presented in Table 1. Exercising and non-exercising control patients, were randomised to receive either their standard (STD) bicarbonate therapy, or additional (XS) sodium bicarbonate to achieve a target plasma bicarbonate of $29 \mathrm{mmol} / \mathrm{l}$. All gave informed consent. The study was approved by the Medicines and Health Regulatory Authority and Local Ethics Committee. 
Table 1. Baseline characteristics for those patients who completed the study. Values are displayed as median and range.

\begin{tabular}{|c|c|c|c|c|c|c|c|c|c|c|c|c|}
\hline $\begin{array}{l}\text { Patient } \\
\text { Involvement }\end{array}$ & $\begin{array}{l}\text { Completed } \\
\text { (n) }\end{array}$ & $\begin{array}{l}\text { STD } \\
\text { Bicarb } \\
\text { (n) }\end{array}$ & $\begin{array}{l}\text { XS } \\
\text { Bicarb } \\
\text { (n) }\end{array}$ & Males & Females & $\begin{array}{l}\text { Age } \\
\text { (years) }\end{array}$ & $\begin{array}{l}\text { Weight } \\
\text { (kg) }\end{array}$ & $\begin{array}{l}\text { Height } \\
\text { (m) }\end{array}$ & BMI & $\begin{array}{l}\text { Serum } \\
\text { Creatinine } \\
(\mu \mathrm{mol} / \mathrm{l})\end{array}$ & $\begin{array}{l}\text { eGFR } \\
\text { (ml/min) }\end{array}$ & $\begin{array}{l}\text { Basal } \\
\text { Plasma } \\
\text { Bicarbonate } \\
(\mathbf{m m o l} / \mathbf{l})\end{array}$ \\
\hline $\begin{array}{l}\text { Exercising } \\
+ \text { Biopsy }\end{array}$ & 15 & 9 & 6 & 8 & 7 & $\begin{array}{l}62 \\
(50-73)\end{array}$ & $\begin{array}{l}80 \\
(53-116)\end{array}$ & $\begin{array}{l}1.70 \\
(1.48- \\
1.92)\end{array}$ & $\begin{array}{l}29.9 \\
(20.4- \\
33.5)\end{array}$ & $\begin{array}{l}190 \\
(132-506)\end{array}$ & $\begin{array}{l}26 \\
(11-36)\end{array}$ & $25(19-27)$ \\
\hline $\begin{array}{l}\text { Non- } \\
\text { Exercising } \\
\text { controls }\end{array}$ & 14 & 8 & 6 & 8 & 6 & $\begin{array}{l}56 \\
(31-83)\end{array}$ & $\begin{array}{l}85.5 \\
(60-125)\end{array}$ & $\begin{array}{l}1.76 \\
(1.55- \\
1.87)\end{array}$ & $\begin{array}{l}29.2 \\
(19-38)\end{array}$ & $\begin{array}{l}205 \\
(139-427)\end{array}$ & $\begin{array}{l}28 \\
(12-37)\end{array}$ & $27(19-30)$ \\
\hline $\begin{array}{l}\text { Non- } \\
\text { Exercising } \\
\text { controls } \\
+ \text { Biopsy }\end{array}$ & 11 & 8 & 3 & 5 & 6 & $\begin{array}{l}50 \\
(31-83)\end{array}$ & $\begin{array}{l}85.5 \\
(66-115)\end{array}$ & $\begin{array}{l}1.73 \\
(1.57- \\
1.87)\end{array}$ & $\begin{array}{l}29.6 \\
(19-38)\end{array}$ & $\begin{array}{l}214 \\
(154-427)\end{array}$ & $\begin{array}{l}24 \\
(12-33)\end{array}$ & $26(19-30)$ \\
\hline
\end{tabular}




\section{Exercise training}

The exercise training has been described previously (Kosmadakis et al. 2011). Briefly, patients were instructed to walk five times a week for a minimum of 30 minutes for six months. Patients walked at a perceived exertion of 12-14 on the Borg scale (Borg. 1982), and were seen by a member of the exercise team once a month to check progress and address any problems (Kosmadakis et al. 2011).

\section{Exercise tolerance test}

This has been described previously (Kosmadakis et al. 2011), patients performed an exercise tolerance test at baseline consisting of 30 minutes walking on a motorised treadmill at a $1 \%$ incline while wearing an electronic heart rate monitor. Every 2 minutes, the patient was asked to self-report their effort level using the Borg Rating of Perceived Exertion (RPE) (Borg. 1982) scale and the speed of the treadmill was adjusted to maintain a score of $12-14$ ("somewhat hard"). The treadmill speed profile of each individual's tolerance test was recorded and repeated exactly after 1 month or 6 months to present the same absolute workload, with RPE again recorded every 2 minutes and compared to baseline. Blood samples were drawn at rest and immediately post exercise for the measurement of blood lactate by enzymatic assay to determine the acute effect of exercise.

These lactate measurements were the only measurements in the study that were performed in association with an acute exercise test. All other measurements refer to chronic studies performed on samples taken 24 hours post-exercise.

\section{Dietary intake}

Dietary intake was assessed from 3-day diet diaries that were completed at baseline and after six months 


\section{Biopsies}

At baseline and after six months biopsies were taken from the right vastus lateralis using a Bergstrom needle, with the patient in the supine position, after overnight fast and at least $24 \mathrm{~h}$ after the last exercise training session. Tissue was immediately frozen in liquid nitrogen after removal of visible fat or connective tissue, and freeze-dried. Separate fragments were taken for mRNA analysis, immunoblotting and amino acid determination by HPLC to determine the chronic effects of exercise training.

\section{Real-time polymerase chain reaction (PCR) analysis of mRNAs}

RNA was isolated using TRIzol® (Invitrogen, UK) and reverse transcribed to cDNA using an AMV reverse transcription system (Promega, Madison,WI). Gene expression of SNAT2 was determined using SYBR green (Applied Biosystems) gene-specific primers (shown in Table 2) and normalised to RPL30 whose expression was unchanged by the exercise training programme. The RT-qPCR reactions were carried out on an Applied Biosystems Light Cycler with an initial $95^{\circ} \mathrm{C}$ step for 15 seconds, followed by $40 \mathrm{X}$ at $95^{\circ} \mathrm{C}$ for 15 seconds and $58^{\circ} \mathrm{C}$ for 1 minute. All samples from each patient were analysed on the same 96 well plate to allow for direct relative comparisons.

Table 2. Details of primers used for RT-qPCR

\begin{tabular}{|l|l|l|}
\hline Gene & Forward 5'-3' & Reverse 5'-3' \\
\hline SNAT2 & AGTGGAATCCTTGGGCTTTC & TCCTTCATTGGCAGTCTTCA \\
\hline RPL30 control & & \\
gene & GGGTACAAGCAGACTCTGAA & CCAGTTTTAGCCAACATAGC \\
\hline
\end{tabular}

Primers, probes and internal controls for MAFbx and MuRF-1 were supplied as Taqman gene expression assays (Applied Biosystems, Warrington, UK: MAFbx Hs00369714_m1, 
MuRF-1 Hs00822397_m1, RPL30 Hs00265497_m1). Relative expression was calculated using the Pfaffl ratio (Pfaffl. 2001). Further details are described in Supplementary Methods.

\section{Amino acid determination by high performance liquid chromatography (HPLC)}

Plasma and freeze-dried muscle were deproteinised using $0.3 \mathrm{~mol} / /$ perchloric acid (PCA). Following centrifugation $\left(13,000 \mathrm{~g}, 15 \mathrm{~min}, 4^{\circ} \mathrm{C}\right)$ the acidic supernatant was neutralised by vortexing with an equal volume of tri-n-octylamine/1,1,2-trichlorotrifluoro-ethane (22:78 $\mathrm{vol} / \mathrm{vol})$. The neutralised aqueous phase was used in the determination of amino acid concentration using an Agilent 1100 High-performance liquid chromatograph with Zorbax eclipse AAA column $(4.6 \times 75 \mathrm{~mm}, 3.5 \mu \mathrm{m})$ with pre-column derivatisation using Orthopthalaldehyde (Agilent, UK) and Fluorenylmethyloxycarbonyl chloride (Agilent, UK) and ultraviolet post-column detection. Amino acid concentrations in the biopsies are expressed as mmol per $\mathrm{L}$ of intracellular water. Further details are described in Supplementary Methods.

\section{3-Methyl histidine analysis}

Consenting patients underwent a diet free from animal protein for 4 days and collected a $24 \mathrm{~h}$ urine sample on the final day of the diet commencing the urine collection at least 12 hours after the last walking exercise. The urine volume was measured and aliquots were stored at $-20^{\circ} \mathrm{C}$ prior to 3-methylhisitidine (3-MH) analysis by High Performance Liquid Chromatography (HPLC) as described above. 3-MH concentrations were corrected for muscle mass using lean body mass (LBM) values obtained from DEXA measurements (Kosmadakis et al. 2011).

\section{Immunoblotting}

Lysates were prepared from freeze-dried muscle by homogenisation in $90 \mu \mathrm{l} / \mathrm{mg}$ lysis buffer followed by centrifugation to remove insoluble material as described by (Karlsson et al. 
2004). Insoluble pellets were retained for determination of the $14 \mathrm{kDa}$ actin fragment (Du et al. 2004; Workeneh et al. 2006). Lysates were subjected to SDS-PAGE using $12.5 \%$ gels on a MiniProtean3 system (Bio-Rad, UK). Proteins were transferred onto nitrocellulose membrane, blocked for $1 \mathrm{~h}$ with Tris-buffered saline $(\mathrm{pH} 7.6)$ with $5 \%(\mathrm{w} / \mathrm{v})$ skimmed milk and $0.1 \%(\mathrm{v} / \mathrm{v})$ Tween 20 detergent. Membranes were then incubated with primary antibody in blocking buffer overnight. Antibodies for Phospho(Ser $\left.{ }^{235 / 236}\right)$-rpS6, total rpS6, Phospho $\left(\mathrm{Ser}^{473}\right)-$ Akt, Total Akt, Phospho(Thr $\left.{ }^{389}\right)-\mathrm{p}^{70} \mathrm{~S} 6 \mathrm{~K}$, Total $\mathrm{p}^{70} \mathrm{~S} 6 \mathrm{~K}$, Phospho(Ser $\left.{ }^{65}\right)-4 \mathrm{E}-$ BP1 and Total 4E-BP1 were from Cell Signalling Technology (Hertfordshire, UK) and used at 1:1000. Antibody against the 14-kDa actin fragment (anti-actin clone AC40) was from Sigma Aldrich (Dorset, UK) and used at 1:500. Bands were quantified using a Bio-Rad GS7000 densitometer and Molecular Analyst v1.4 software.

\section{Statistical Analysis}

Results are presented as medians and range or means \pm SE and absolute frequencies. Due to the small number $(n=3)$ of patients in the non-exercising Control XS bicarbonate group who gave muscle biopsies, this group was excluded from the analysis. This applied to analysis of amino acids, mRNA expression of MuRF-1,MAFbx and SNAT2, density of 14 kDa actin fragment and Akt phosphorylation.

Prior to analysis all data sets were first tested for normal distribution using the Kolmogorov Smirnov test. One way ANOVA was used for examining differences between treatment groups at baseline for age, weight, height, BMI, creatinine, eGFR and bicarbonate. Six month post-treatment values for arterial $\mathrm{pH}$ and venous bicarbonate were also similarly analysed. Scheffé post hoc testing was employed for multiple between group comparisons. Two way factorial ANOVA was used for dietary intake, and 3-MH excretion, with dose and group as factors with Scheffé for post hoc testing. 
One way Kruskal-Wallis ANOVA was employed when there was evidence of non-normal distribution in data sets. This was used in analysis of amino acids, mRNA expression of MuRF-1,MAFbx and SNAT2, density of $14 \mathrm{kDa}$ actin fragment, Akt phosphorylation and blood lactate concentration. Dunn's test was used for post hoc testing between groups.

Due to patient variability in baseline amino acid concentrations, changes in intramuscular amino acid concentrations at the 6 month time point were expressed as a percentage of the baseline concentration, re: $100 \%$ reference value indicating no change. Additionally, the binomial test was employed for analysis of observed and expected frequencies for increases and decreases in median amino acid concentration values.

For all statistical tests changes were regarded as statistically significant when $\mathrm{P}<0.05$ and when appropriately adjusted for direct multiple comparisons. The $\mathrm{P}$ value returned by each statistical test is quoted to 2 significant figures, except where space was limited in figure and table legends and where groups of $P$ values are returned, in which case significance boundaries (e.g. $\mathrm{P}<0.05)$ are quoted. 


\section{$\underline{\text { Results }}$}

\section{Completion rates and effectiveness of bicarbonate supplementation}

Completion rates have been documented previously (Kosmadakis et al. 2011) and are presented along with baseline characteristics of the patients in Table 1.

The effect of additional bicarbonate on arterial $\mathrm{pH}$ and venous bicarbonate is shown in Table 3. At baseline no significant difference was observed between the acid-base status of patients in STD and XS groups. In contrast six months of additional oral bicarbonate resulted in significantly raised venous bicarbonate levels above that in the STD groups (One way ANOVA $F_{3,28}=6.9 p=0.0013$ ). Control STD vs control XS showed a mean increase of $3.6 \mathrm{mmol} / \mathrm{L}(\mathrm{p}=0.029)$. For exercise STD vs exercise $X S$ there was an increase of 2.3 $\mathrm{mmol} / \mathrm{L}(\mathrm{p}=0.0023)$. No adverse effects were reported by XS bicarbonate patients. 
Table 3. Effect of STD and XS bicarbonate therapy on blood bicarbonate levels and pH. Data are presented as mean and standard deviation. * denotes significant difference from corresponding baseline value $(\mathrm{P}<0.05){ }^{*}$ denotes significant difference from exercising STD group $(\mathrm{P}<0.05){ }^{a}$ denotes significant difference from non-exercising STD group. Data are from patients who gave a biopsy only.

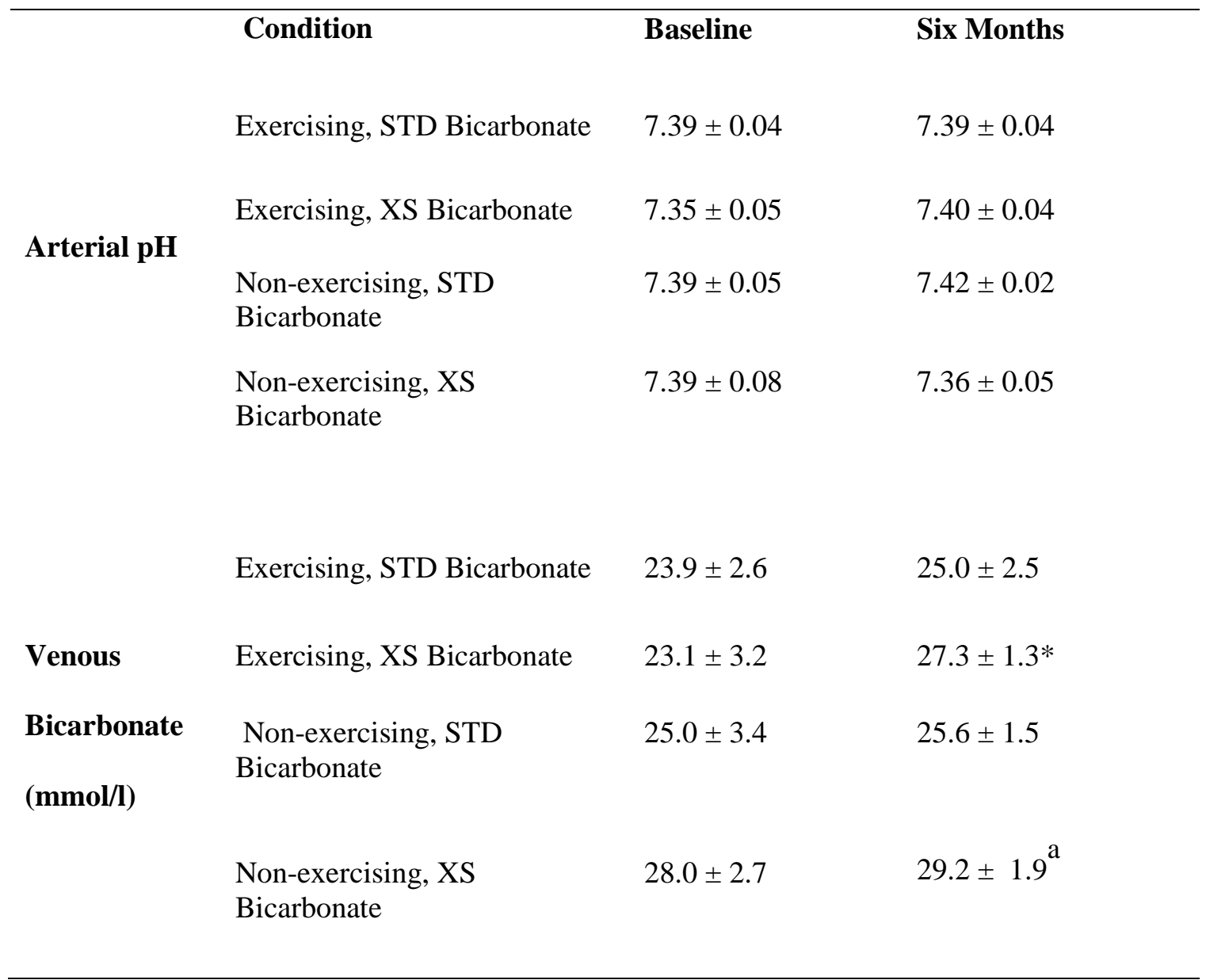

\section{Blood lactate response}

As worsening of pre-existing acidosis by exercise-induced lactate production is theoretically an effect of exercise in CKD, blood lactate accumulation was measured following a 30 minute treadmill exercise test (see Supplementary Methods) at baseline and following training. At baseline, 30 minutes of treadmill exercise significantly increased blood lactate concentration (Table 4). One or six months of training with STD bicarbonate had no significant effect on this lactate response to acute exercise. In contrast, one month of 
training with XS bicarbonate led to a significant blunting (Kruskal-Wallis ANOVA $P=0.03$ ) of this lactate response when compared with baseline (Dunn's test $P=0.034$ ) in Table 4. After six months of exercise with XS bicarbonate this apparent blunting persisted, but was not significant. No statistically significant effect was detected in non-exercising patients (Table 4).

Table 4. Effect of exercise training on blood lactate concentration (all concentrations in $\mathrm{mmol} / \mathrm{l}$ ) expressed as the rise in blood lactic acid concentration derived from measurements performed at rest and following an acute $\mathbf{3 0}$ minute treadmill exercise test. Data are from all patients.

*Denotes a significant difference versus the corresponding value at baseline

${ }^{a}$ Denotes a significant difference from the corresponding value measured at rest in each exercise test $(P<0.05)$.

$N D=$ Not determined

\section{Baseline}

One Month

Six Months

Patient Group

$\begin{array}{lllllllll} & & \mathbf{3 0} & & & & & \\ \text { At rest } & \text { Post } & \text { min } & \text { At rest } & \text { Post } & \begin{array}{l}\text { 30 } \\ \text { min }\end{array} & \text { At } & \text { Post } & \text { min } \\ & \text { test } & \text { Rise } & & \text { rest } & \text { test } & \text { Rise }\end{array}$

Exercising

STD Bicarbonate

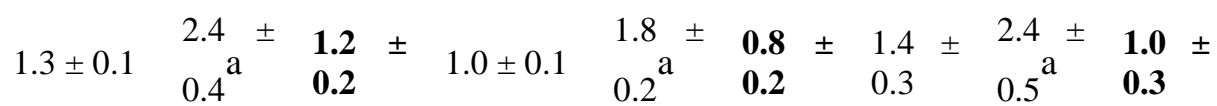

Exercising

XS Bicarbonate

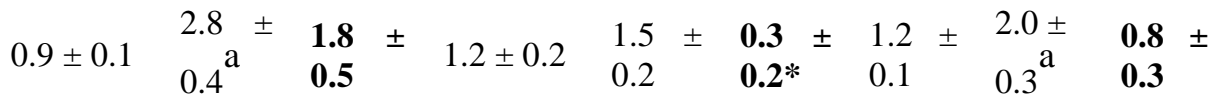

Non-exercising

STD Bicarbonate

$\begin{array}{lll}1.2 \pm 0.2 & 2.1 \pm & \mathbf{0 . 9} \\ 0.4 & \mathbf{0} & \mathbf{0 . 3}\end{array}$

ND ND

$0.8 \pm 1.2 \pm 0.4 \pm$

Non-exercising

XS Bicarbonate

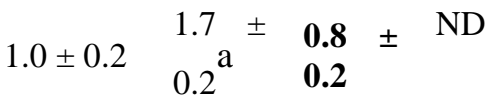

ND

ND

$0.9 \pm 2.2 \pm \mathbf{1 . 3} \pm$

$\begin{array}{lll}0.1 & 0.4^{\mathrm{a}} & \mathbf{0 . 4}\end{array}$




\section{Intramuscular amino acid concentrations}

To assess the chronic effects of exercise and acid-base changes on muscle metabolism, vastus lateralis biopsies were studied at baseline and six months. Twenty six of the patients consented to giving biopsies. Baseline characteristics of biopsied patients are compared with the complete (biopsied + non-biopsied) groups in Table 1 .No characteristics showed significant differences between these groups (One-way ANOVA). Fasted biopsy amino acid data are presented in Figures 1 and 2 and Table 5 (and comprehensive data for all amino acids are tabulated as Supplementary Data).

Although baseline amino acid concentrations varied considerably between individuals (Figure 2), no statistically significant differences were detected by one way ANOVA at baseline between the patient groups. The distribution of median concentrations in the groups were similar to that reported previously in resting muscle in CKD (Bergstrom et al. 1990).

Due to the inter-patient variability in the baseline amino acid concentrations, changes in muscle amino acid concentrations were expressed as percentage changes at 6 months expressed relative to their baseline values (Figure 1 and Table 5). No significant depletion in individual amino acids was apparent in the non-exercising control group. There was evidence of an approximately even frequency distribution in increased and decreased median concentrations across the 18 amino acids (10:8; increase: decrease, binomial test $P=0.82$ ). When analysed by Kruskal-Wallis ANOVA, significant changes (ranging from $P=0.04-0.002$ ) were returned for 10 out of 18 amino acids (Table 5). Compared against the non-exercising controls, the exercise STD group by post hoc testing returned significant decreases $(P<0.016)$ in 5 of the 10 amino acids. Evidence of marginally significant decreases $(P=0.03$ and $P=0.04)$ was observed for leucine and lysine. These depletion 
responses to training in individual patients in the STD bicarbonate group are shown for four representative amino acids in Figure 2.

In contrast, when compared against the non-exercising controls, the exercise XS group returned significant increases in median concentration for 2 of the 18 amino acids. Whilst post hoc analysis did not return significant changes for all amino acids it is noteworthy that broad support of the contrast in median directional changes was provided by the binomial test. When compared with the non-exercising control group, the increase:decrease ratio in the exercise STD group in Table 5 was 2:16; $(P=0.0005)$ contrasting with 14:4 $(P=0.012)$ for the exercise XS group.

Analysis by Kruskal Wallis ANOVA of the sum of the branched chain amino acids (BCAA i.e. L-Leu, L-Ile and L-Val) (Table 5) returned a highly significant difference ( $P=0.009)$. Dunn's post hoc test also returned highly significant differences between the Exercise STD and Exercise XS groups $(P=0.0019)$ and between the Exercise STD and Control STD groups $(P=0.001)$. 
Table 5. Change in muscle amino acid concentrations at 6 months expressed as a percentage of the value at baseline. Data are presented as median and full range. $\dagger$ denotes significant difference from Non-Exercise Control STD group as determined by Dunn's post hoc test and therefore values are regarded as significant only when $\mathrm{P}<0.016$ rather than $\mathrm{P}<0.05$. BCAA denotes sum of branched chain amino acids.

\begin{tabular}{|c|c|c|c|c|}
\hline Amino Acid & $\begin{array}{l}\text { Non-exercising } \\
\text { Control STD } \\
\text { (\%Change) }\end{array}$ & $\begin{array}{l}\text { Exercise STD } \\
\text { (\% Change) }\end{array}$ & $\begin{array}{l}\text { Exercise XS } \\
\text { (\% Change) }\end{array}$ & $\begin{array}{l}\text { Kruskal-Wallis } \\
\text { (P Value) }\end{array}$ \\
\hline Glu & $125(49-312)$ & $47(7-295)^{\dagger}$ & 209 (52-391) & 0.002 \\
\hline Asn & 90 (36-297) & $49(11-151)$ & $268(26-344)$ & 0.03 \\
\hline Ser & $134(33-300)$ & $57(4-135)$ & 218 (43-296) & 0.03 \\
\hline Gln & $130(6-260)$ & $54(9-351)$ & $174(20-191)$ & 0.31 \\
\hline His & $152(25-983)$ & $58(5-493)$ & $127(45-273)$ & 0.44 \\
\hline Gly & $79(41-349)$ & $72(9-628)$ & 263 (39-335) & 0.17 \\
\hline Thr & $63(29-118)$ & $45(6-168)$ & $220(48-595)^{\dagger}$ & 0.022 \\
\hline Arg & $93(42-482)$ & $49(7-107)^{\dagger}$ & $163(50-247)$ & 0.01 \\
\hline Ala & $91(8-884)$ & $42(1-118)$ & $101(54-287)$ & 0.07 \\
\hline Tyr & 244 (14-658) & $63(5-632)$ & $272(19-356)$ & 0.18 \\
\hline Cys & 75 (25-396) & $73(3-240)$ & $30(2-355)$ & 0.60 \\
\hline Val & $144(42-390)$ & $54(4-105)^{\dagger}$ & $169(27-308)$ & 0.01 \\
\hline Met & 74 (8-191) & $84(5-441)$ & $216(4-478)$ & 0.40 \\
\hline Tryp & $118(45-635)$ & $49(16-100)$ & $99(25-331)$ & 0.17 \\
\hline Phe & $166(51-591)$ & $21(12-159)^{\dagger}$ & $193(19-444)$ & 0.01 \\
\hline Ile & $158(56-789)$ & $65(9-132)^{\dagger}$ & $163(67-302)$ & 0.04 \\
\hline Leu & $95(51-354)$ & $54(17-108)$ & $205(49-573)$ & 0.03 \\
\hline Lys & $177(46-641)$ & $39(4-91)$ & $123(69-225)$ & 0.04 \\
\hline All BCAA & $113(51-298)$ & $54(10-108)^{\dagger}$ & $163(67-286)^{\dagger}$ & 0.009 \\
\hline
\end{tabular}


To determine the possible contribution of extracellular amino acid depletion to the chronic intramuscular depletion observed in exercising STD bicarbonate patients (Figure 1 and 2), fasted plasma amino acids were also measured in the biopsied patients (Figure 3). Significant depletion was only observed for L-Arg: indeed for most of the amino acids the plasma concentrations tended to rise (Figure 3).

\section{Amino acid concentration gradients}

Falling intramuscular amino acid concentrations with rising extracellular concentrations in exercising STD patients resulted in a marked long-term collapse of muscle/plasma concentration gradients after six months. For L-Ala, the gradient declined from median 11.5 (range 1.8-75.3) at baseline to 2.9 (range 0.07-7.08) (Kruskal-Wallis ANOVA P=0.008). Significant collapse, typically to $<1 / 3$ of baseline, was detected for 11 of the 17 amino acids assayed (see supplementary data).

A major transport protein which maintains such gradients by active transport of amino acids (notably L-Ala) is the slc38a2/SNAT2 transporter. However, six months of exercise \pm additional bicarbonate, had no effect on SNAT2 mRNA expression in vastus lateralis (Table $6)$. 
Table 6. Changes in the expression of the slc38a2/SNAT2 amino acid transporter in vastus lateralis determined by Q-PCR following six months with or without exercise with standard (STD) or additional (XS) bicarbonate therapy. Data are presented as the Pfaffl Ratio (see Methods) which, by definition, has a baseline value of 1.00 .

\section{Baseline}

STD Bicarbonate

$1.0(0.02-2.9)$

Exercising

1.00

Non-

exercising
Six Months

XS Bicarbonate

$0.9(0.1-3.3)$

$0.74(0.1-1.0)$

\section{Dietary intake}

In principle, differences in food intake between exercising and non-exercising STD bicarbonate patients may have contributed to the effects in Figures 1a and 2. Two way factorial ANOVA returned no significant changes for intake of energy, carbohydrate or fat (Table 7). Protein intake fell after six months both in exercising and non-exercising patients, with no significant difference between them. It is therefore unlikely that dietary changes are sufficient to explain the observed effects on muscle free amino acids. 
Table 7. Estimated dietary intake of energy, carbohydrate (CHO), protein and fat at baseline and following six months with or without exercise for patients on standard (STD) bicarbonate therapy. Data are from all patients.

*denotes significant change from the corresponding value at baseline ( $P=0.03$ for exercising patients and $P=0.03$ for non-exercising patients).

\begin{tabular}{|c|c|c|c|c|c|c|c|c|}
\hline & \multicolumn{4}{|l|}{ Baseline } & \multicolumn{4}{|c|}{ Six Months } \\
\hline & $\begin{array}{l}\text { Energy } \\
\text { (kcal/kg } \\
\text { bw) }\end{array}$ & $\begin{array}{l}\text { CHO } \\
(\mathrm{g} / \mathrm{kg} \\
\text { bw) }\end{array}$ & $\begin{array}{l}\text { Protein } \\
\text { (g/kg } \\
\text { bw) }\end{array}$ & $\begin{array}{l}\text { Fat } \\
\text { (g/kg bw) }\end{array}$ & $\begin{array}{l}\begin{array}{l}\text { Energy } \\
\text { (kcal/kg } \\
\text { bw) }\end{array}\end{array}$ & $\begin{array}{l}\text { CHO } \\
\text { (g/kg bw) }\end{array}$ & $\begin{array}{l}\text { Protein } \\
\text { (g/kg bw) }\end{array}$ & $\begin{array}{l}\text { Fat } \\
\text { (g/kg bw) }\end{array}$ \\
\hline Exercising & $24.5 \pm 3.2$ & $\begin{array}{l}3.1 \pm \\
0.3\end{array}$ & $1.0 \pm 0.1$ & $\begin{array}{l}1.0 \pm \\
0.2\end{array}$ & $\begin{array}{l}19.2 \pm \\
1.2\end{array}$ & $2.5 \pm 1.2$ & $\begin{array}{l}0.8 \pm \\
0.03^{*}\end{array}$ & $\begin{array}{l}0.7 \pm \\
0.1\end{array}$ \\
\hline $\begin{array}{l}\text { Non- } \\
\text { exercising }\end{array}$ & $26.6 \pm 5.5$ & $\begin{array}{l}3.2 \pm \\
0.8\end{array}$ & $1.1 \pm 0.2$ & $\begin{array}{l}1.0 \pm \\
0.2\end{array}$ & $\begin{array}{l}22.0 \pm \\
1.0\end{array}$ & $\begin{array}{l}2.7 \pm \\
0.6\end{array}$ & $0.8 \pm 0.2 *$ & $\begin{array}{l}0.8 \pm \\
0.1\end{array}$ \\
\hline
\end{tabular}

\section{Intramuscular signals}

In view of the negative impact that lactic acidosis (Table 4) and amino acid depletion (Figures 1a, 2) following exercise might have on muscle mass, and in view of the apparent blunting of these detrimental effects of exercise that occurred with XS bicarbonate (Table 4; Figure $1 b$ ), it would be predicted that beneficial effects of exercise on protein catabolic signals would be observed more readily in exercising XS bicarbonate patients. Expression of E3-ligases MAFbx and MuRF-1, as markers of proteolysis through the UPP, showed a pattern consistent with this (Figure 4). For comparison of the three groups (exercise STD, exercise XS, control STD) Kruskal-Wallis ANOVA returned a $P$ value of $P=0.03$. Post hoc testing using Dunn's test revealed that after six months of training, significant suppression of expression relative to baseline was only observed for MuRF-1 $(P=0.03)$ in XS bicarbonate patients. A similar but statistically insignificant trend was observed for MAFbx $(P=0.11)$.

No such beneficial effect of exercise plus bicarbonate was observed on Akt activation (Figure 5) which, at least in acute exercise, is regarded as a measure of anabolic signalling 
through PI-3-kinase/Akt. There was also no significant depletion of the $14 \mathrm{kDa}$ Actin fragment in the biopsies (Figure 6) (a marker of caspase-dependent myofibrillar proteolysis) (Workeneh et al. 2006)(Du et al. 2004), which has previously been reported to decrease in exercising CKD patients (Workeneh et al. 2006). This did show a tendency to decline relative to baseline in exercising STD patients, but this was not statistically significant (KruskalWallis ANOVA, $\mathrm{P}=0.096$ ).

Possibly because of this failure of six months of exercise training ( \pm additional bicarbonate) to influence Akt and caspase activation, the chronic effects of exercise on overall rates of myofibrillar protein catabolism assessed from 3-methyl-histidine (3-MH) excretion were unchanged (Table 8). This was true irrespective of whether 3-MH excretion was corrected for LBM variation by calculating 3-MH/creatinine excretion ratio (Elia et al. 1981), or by expressing 3-MH relative to LBM measured directly using DEXA (Kosmadakis et al. 2011) (Table 8). 
Table 8. 3-methyl-histidine (3-MH) excretion rates corrected for creatinine (Crnn) or for lean body mass (LBM) (DEXA) in exercising patients (a) or in non-exercising control patients (b) who received standard (STD) or additional (XS) bicarbonate therapy. Data are from all patients.

\begin{tabular}{|c|c|c|c|c|}
\hline (a) & $\begin{array}{l}\text { Baseline } \\
\text { STD }\end{array}$ & $\begin{array}{l}\text { Six } \\
\text { Months } \\
\text { Exercise } \\
\text { STD }\end{array}$ & $\begin{array}{l}\text { Baseline } \\
\text { XS }\end{array}$ & $\begin{array}{l}\text { Six Month } \\
\text { Exercise } \\
\text { XS }\end{array}$ \\
\hline $\begin{array}{l}\text { 3-MH/Creatinine } \\
(\mu \mathrm{mol} / \mathrm{mmol} \mathrm{Crnn} / 24 \mathrm{~h})\end{array}$ & $33.9 \pm 5.9$ & $38.8 \pm 8.1$ & $32.0 \pm 8.9$ & $35.8 \pm 8.0$ \\
\hline $\begin{array}{l}\text { 3-MH/LBM } \\
(\mu \mathrm{mol} / \mathrm{kg} \mathrm{LBM} / 24 \mathrm{~h})\end{array}$ & $10.6 \pm 2.6$ & $9.4 \pm 2.0$ & $9.2 \pm 1.2$ & $12.3 \pm 2.7$ \\
\hline (b) & $\begin{array}{l}\text { Baseline } \\
\text { STD }\end{array}$ & $\begin{array}{l}\text { Six } \\
\text { Months } \\
\text { STD }\end{array}$ & $\begin{array}{l}\text { Baseline } \\
\text { XS }\end{array}$ & $\begin{array}{l}\text { Six Months } \\
\text { XS }\end{array}$ \\
\hline $\begin{array}{l}\text { 3-MH/Creatinine } \\
(\mu \mathrm{mol} / \mathrm{mmol} \mathrm{Crnn} / 24 \mathrm{~h})\end{array}$ & $37.5 \pm 6.9$ & $29.0 \pm 3.9$ & $47.2 \pm 13.9$ & $60.8 \pm 10.1$ \\
\hline $\begin{array}{l}\text { 3-MH/LBM } \\
(\mu \mathrm{mol} / \mathrm{kg} \mathrm{LBM} / 24 \mathrm{~h})\end{array}$ & $8.6 \pm 1.7$ & $9.0 \pm 1.4$ & $12.4 \pm 4.1$ & $16.3 \pm 3.9$ \\
\hline
\end{tabular}

\section{Intramuscular signals regulating protein synthesis}

Amino acid depletion (Figures 1a and 2) might also influence protein synthesis, through amino acid-responsive mTORC1 signalling which regulates translation (Proud. 2004). However, as reported previously (Dreyer et al. 2008) in fasted resting muscle, mTORC1dependent signals were almost undetectable. No significant phosphorylation of targets of mTORC1 (i.e. $\mathrm{p}^{70} \mathrm{~S} 6$-kinase, ribosomal protein $\mathrm{S} 6$, or eukaryotic initiation factor $4 \mathrm{E}$-binding protein 1) was detected at baseline or 6 months under any conditions studied (data not shown). 


\section{Discussion}

This study aimed to test the hypothesis that exercise plus additional alkali exerts beneficial effects on muscle amino acid and protein metabolism which are not obtained with exercise alone. The reasoning behind this was that exercise in non-dialysed patients might result in transient worsening of acidosis through exercise-induced lactate generation, thus negating benefits of exercise. The main finding of this study was a striking depletion of free amino acids after 6 months of exercise in those patients who exercised whilst on their standard bicarbonate therapy only. A decrease in the expression of the E3 ligase MuRF1 was observed in patients on XS bicarbonate.

\section{Blood lactate response}

Acid-base and blood lactate measurements suggested that additional (XS) bicarbonate was effective in two ways. Firstly it raised the circulating bicarbonate concentration (Table 3), thus improving acid-buffering capacity. Secondly, in exercising patients, it apparently reduced the rise in blood lactate following acute exercise (Table 4). The reason for this blunting of the rise in blood lactate is unknown. Theoretically such changes in lactate concentration reflect a complex balance between effects on lactate efflux from skeletal muscle and uptake by non-exercising muscle, liver and other tissues.

Muscle $\mathrm{pH}$ in the interstitial fluid or in the cytosol of the myocytes was not measured in the present study, but it has been shown elsewhere that the normal intracellular acidification of muscle by lactate during exercise is enhanced in CKD. Measurements using ${ }^{31} \mathrm{P}-\mathrm{NMR}$ (Durozard et al. 1993; Kemp et al. 2004) showed greater decline in sarcosolic pH during aerobic exercise and slower post-exercise recovery. Furthermore, in healthy individuals it has been shown that acidosis, induced using $\mathrm{NH}_{4} \mathrm{Cl}$ or diet manipulation reduces exercise capacity (Greenhaff et al. 1987; Jones et al. 1977). It is possible therefore, that additional bicarbonate blunts onset of acidification and fatigue during exercise, allowing more prolonged/intense exercise, and enhanced training effects which may suppress lactate 
production by the exercising muscle in CKD patients (MacRae et al. 1992). However, direct proof of this explanation awaits future studies of this type in which training intensity is rigorously measured.

\section{Amino acid depletion}

In the absence of XS bicarbonate, profound intramuscular amino acid depletion was observed in the nine biopsied patients who exercised for six months, but not in the eight control patients who did not exercise (Figure 1a and 2). Furthermore, the direction of change over the whole group of 18 amino acids studied here was predominantly downwards in these exercising STD patients, in contrast to the predominant upward trend that was observed in the exercising XS patients. Of particular concern in the exercising STD patients is depletion of the branched chain amino acids, including L-Leu (Figure 2 and Table 5) which exerts important anabolic effects in skeletal muscle (Matthews. 2005). It was noted here (Kosmadakis et al. 2011) that small body composition improvements (reduced fat mass, and marginally significant increase in LBM) occurred after one month's exercise but were not sustained at six months (Kosmadakis et al. 2011). The observed amino acid depletion may have limited this response. Furthermore, if such depletion occurs consistently following exercise in CKD, this may explain why it has sometimes proved difficult to achieve more than modest increases in LBM by exercise alone (Cheema et al. 2007a; Cheema et al. 2007b; Johansen et al. 2006; Kopple et al. 2007) and why anabolic responses are enhanced by combining exercise with feeding (Biolo et al. 1997; Majchrzak et al. 2008).

It should be emphasised that this depletion was a long-term stable effect obtained under fasting conditions at least $24 \mathrm{~h}$ after the last training session and cannot therefore reflect acute effects of exercise or amino acid/protein ingestion. For this reason it would be of interest in future studies of this type to compare the acute effects of exercise on amino acid 
profiles in these patients and any modifications that arise from sodium bicarbonate supplementation and/or amino acid ingestion.

Depletion of non-essential amino acids (e.g. L-Ala) in exercising STD patients is also of concern because of the accompanying collapse of muscle/plasma concentration gradients for these amino acids. Plasma membrane amino acid exchanger proteins use these gradients to drive active accumulation of essential amino acids (e.g. L-Leu) by exchanging intracellular non-essential amino acids (e.g. L-Ala) for extracellular L-Leu (Baird et al. 2009; Evans et al. 2008; Nicklin et al. 2009). Indeed, failure of these gradients could explain depletion of a number of the amino acids observed in Figure 1 and Table 5.

Amino acid depletion accompanying exercise (Figure 1 and 2 and Table 5) has not been reported previously and is reminiscent of the marked depletion occurring in uraemic metabolic acidosis (Bergstrom et al. 1990; Lofberg et al. 1997). This was not observed in exercising XS bicarbonate patients (Figure 1b) and a possible explanation is that depletion in exercising STD patients arose from lactic acidosis.

However, caution is needed about this conclusion for two reasons. Firstly an important limitation is the non-randomised design of the exercise element of the study: for reasons that we have discussed previously (Kosmadakis et al. 2011). Even though patients were randomised to receive additional bicarbonate, we chose not to randomise patients to exercise (Kosmadakis et al. 2011). Secondly, significant drop-out rates are a frequent problem in CKD exercise studies (Kosmadakis et al. 2010). Differences in drop-out rates and numbers of patients consenting to biopsies meant that sample sizes differed between the STD and XS bicarbonate groups. In particular in the non-exercising XS group who gave biopsies, only three patients completed the study (Table 1). No conclusions have therefore 
been drawn on whether additional bicarbonate influenced muscle metabolism in nonexercising patients.

The present study was not designed to investigate mechanism(s) of the observed amino acid depletion. It seems likely however that failure occurred in active amino acid transporters (Hyde et al. 2003), which pump amino acids into muscle. A possible candidate slc38a2/SNAT2 (Mackenzie and Erickson. 2004), is strongly inhibited by acidosis (Baird et al. 2006; Evans et al. 2007; Evans et al. 2008) and inhibited in CKD (Asola et al. 2001). No change was seen in SNAT2 expression (Table 6), but studies in vitro have shown that acidosis directly inhibits this transporter protein (Baird et al. 2006; Zhang et al. 2011) independent of gene expression (Evans et al. 2007; Evans et al. 2008). However this inhibition by acid has previously only been studied acutely, and the corresponding chronic effects of acid on this transporter in the context of exercise and mechanical stress merit further investigation.

\section{Intramuscular signals}

Free amino acid changes could affect protein metabolism via amino acid sensors e.g. mTORC1. However, in the fasted resting conditions here, negligible mTORC1 signalling occurred, consistent with other studies in fasted/resting muscle (Dreyer et al. 2008; Karlsson et al. 2004). Nevertheless, these negligible signals are of practical importance, confirming the fasted state of the patients. Consequently the observed amino acid profiles reflect endogenous pools and not amino acid content of the last meal.

As PI-3K/Akt signalling is a critical regulator of muscle mass in vivo (Bodine et al. 2001a), and is impaired in CKD (Bailey et al. 2006), activation of PI-3K/Akt through exercise could suppress proteolysis through inhibition of caspases and E3-ligase expression (Lecker et al. 2006). Suppression of proteolysis by running or muscle overload has been reported in CKD mice (Wang et al. 2009), accompanied by slightly increased Akt phosphorylation following 
running, and a larger response with overload. In contrast, no Akt phosphorylation change was seen here following exercise (Figure 5). Previous studies have reported that increased Akt phosphorylation reduces E3-ligase expression. The significant decline in E3-ligase expression in the exercising XS patients (Figure 4) therefore seems to have occurred independent of Akt. However, it is important to emphasise that much of the earlier work on exercise and Akt cited above studied the acute effects of exercise which may differ significantly from the chronic effects of exercise studied here.

\section{Myofibrillar proteolysis}

Complete proteolysis of myofibrillar proteins requires caspase-3-dependent cleavage (leading to $14 \mathrm{kDa}$ actin accumulation) (Workeneh et al. 2006) and subsequent degradation of the fragments through the UPP. In practice, even though conditions were found which suppressed E3-ligases, and some decline in $14 \mathrm{kDa}$ actin may have occurred in the STD exercising group, under none of the conditions did they occur simultaneously. Overall suppression of myofibrillar proteolysis (3-MH excretion) was not therefore detected. It should also be noted that exercise may acutely stimulate proteolysis (Phillips et al. 1997), an effect which may persist for some time after exercise has ceased. The urine collections for the $3 \mathrm{MH}$ measurements were made at least $12 \mathrm{~h}$ after the last bout of walking exercise, which should have reduced the effect of any acute exercise-induced stimulation of proteolysis. However, for a more rigorous exclusion of such an effect, the effect of the timing of proteolysis measurements may need to be investigated in subsequent studies of this type.

\section{Conclusion}

The observation that additional bicarbonate in exercising patients apparently resulted in reduced lactate response to acute exercise, reduced E3-ligase expression, and avoidance of the amino acid depletion observed in STD exercising patients, suggests that rigorous acidbase control has an important and previously unsuspected role during exercise therapy in 
CKD. However, even with additional alkali, no net decrease in myofibrillar proteolysis occurred (Table 8), possibly through inadequate activation of PI3-K/Akt. In healthy individuals, resistance exercise stimulates PI3-K/Akt more strongly than aerobic exercise (Nader. 2006). Therefore whether improved LBM in CKD can be achieved in future by combining alkali therapy with resistance exercise warrants further investigation.

\section{Disclosure}

None.

\section{Acknowledgements and funding}

This work was partly supported by Kidney Research UK Grant RP33/1/2007. George Kosmadakis was supported by the Hellenic Society of Nephrology, and João Viana by the Portuguese Foundation for Science and Technology. Part of the patient characteristic data in Tables 1 and 3 ha been published previously.(Kosmadakis et al. 2011) Part of this data has been presented in abstract form previously; "Collapse of intramuscular free amino acid pools in patients with CKD4-5 after 6 months of walking exercise is prevented by alkali supplements". Presented at the International congress on nutrition and metabolism in renal disease, Lausanne, 2010.

\section{Statement of competing financial interests}

None to declare 


\section{Figure Legends}

Figure 1. Summary of changes in intramuscular amino acid concentrations from baseline in vastus lateralis following six months with or without exercise and (a) standard (STD) bicarbonate therapy or (b) additional (XS) bicarbonate therapy.

Data are median amino acid concentrations expressed as a percentage of the corresponding median baseline concentration. Statistical analysis of these changes is presented in Table 5. None of the six month non-exercising data or the six month exercising data with $X S$ bicarbonate differed significantly from baseline.

Figure 2. (Top panels) The effect of 6 months of exercise with standard (STD) bicarbonate therapy on free intramuscular concentrations in vastus lateralis of 4 representative amino acids (L-Ala, L-Thr, L-Leu and L-Val) expressed as mmol / $L$ of intracellular water. (Bottom panels) Control data for non-exercising patients on standard (STD) bicarbonate therapy. Each line represents an individual patient. Statistical analysis of these changes is presented in Table 5. To aid visibility of all the data, the vertical axes are plotted on a logarithmic scale.

Figure 3. Summary of changes in plasma amino acid concentrations from baseline following six months with or without exercise and (a) standard (STD) bicarbonate therapy or (b) additional (XS) bicarbonate therapy.

Data are mean amino acid concentrations expressed as a percentage of the corresponding mean baseline concentration. Data are presented only from patients who gave muscle biopsies. With the exception of $L-A r g(P<0.05$ in both (a) and (b)), none of the amino acids showed significant depletion in response to 6 months of exercise. 
Figure 4. Changes in the expression of the ubiquitin E3-ligases (a) MAFbx and (b) MuRF1, in vastus lateralis determined by Q-PCR following six months with or without exercise with standard (STD) or additional (XS) bicarbonate therapy. Data are presented as the Pfaffl Ratio (see Methods) which, by definition, has a baseline value of 1.00. \# denotes significant difference from baseline $(P<0.05)$.

Figure 5. Phosphorylation of Akt on the Ser 473 residue in vastus lateralis biopsies drawn at baseline and after 6 months from patients on standard (STD) or additional (XS) bicarbonate therapy. Representative immunoblots are shown from exercising patients (a) or from non-exercising control patients (c). Quantification by densitometry of phosphorylated Akt (P-Akt) data pooled from all biopsies is shown for exercising patients (b) and for non-exercising control patients (d). Signal intensity is expressed as a percentage of the signal obtained from a reference lysate of insulin-stimulated L6-G8C5 myotubes that was run in parallel with the patients' lysates on every blot.

Figure 6. Detection of the $14 \mathrm{kDa}$ actin fragment in vastus lateralis biopsies drawn from patients at baseline "0" and after 1 or 6 months. Representative immunoblots are shown from exercising patients $(a, b)$ or from non-exercising control patients $(d, e)$. Patients receiving standard (STD) bicarbonate are shown in (a) and (d). Patients receiving additional (XS) bicarbonate are shown in (b) and (e). A reference lysate " $H$ " prepared from a vastus lateralis biopsy from a single healthy male volunteer (age 47 years) was run on every blot as a quality control. Two exposure times were used when developing the blots: 10 seconds to quantify $42 \mathrm{kDa}$ intact actin and a longer exposure of 10 minutes to quantify the $14 \mathrm{kDa}$ actin fragment. Densitometry performed on these matched pairs of films was used to calculate a $14 k D a / 42 k D a$ ratio which is presented for pooled exercising patients in (c) and for nonexercising control patients in (f). 
Figure 1a

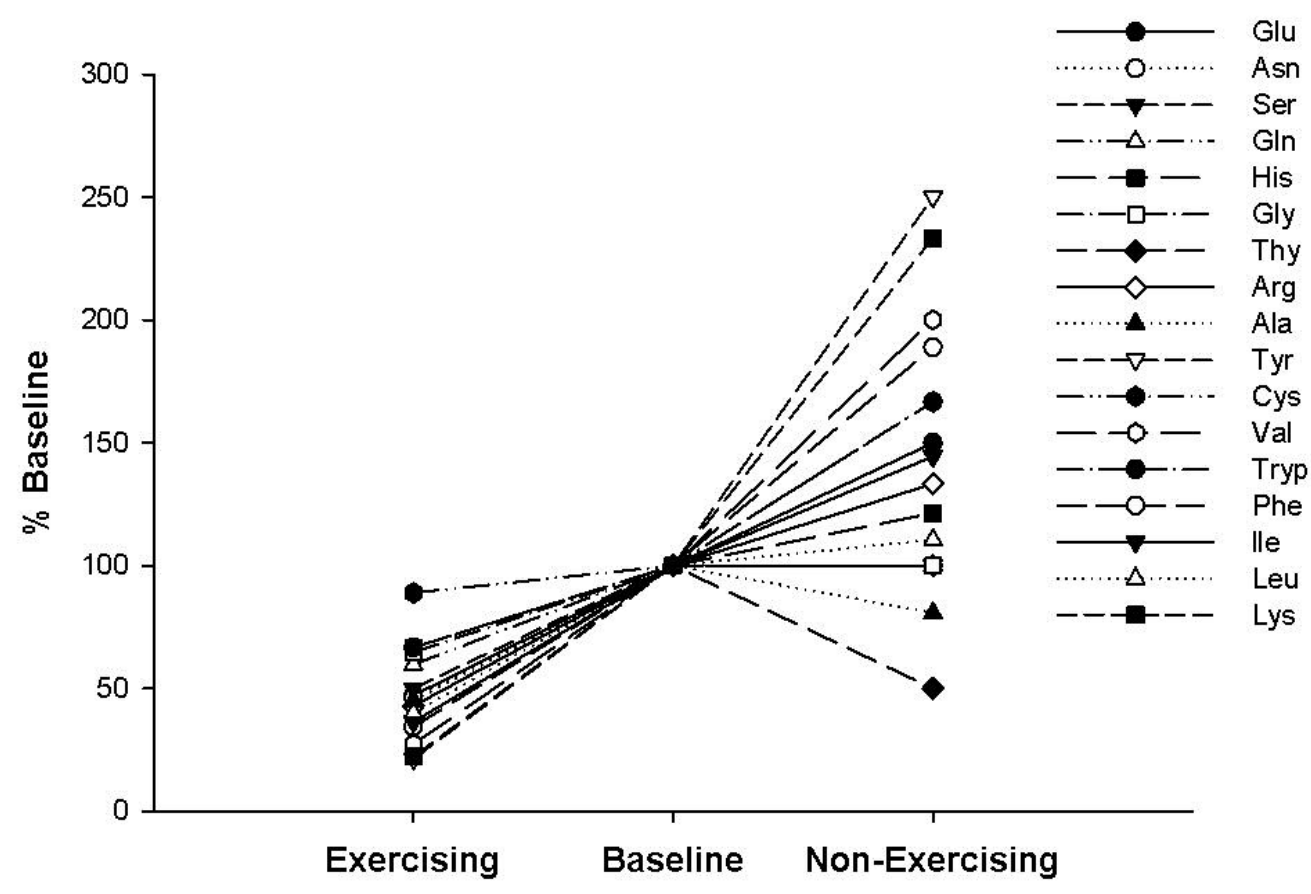

Figure 1b

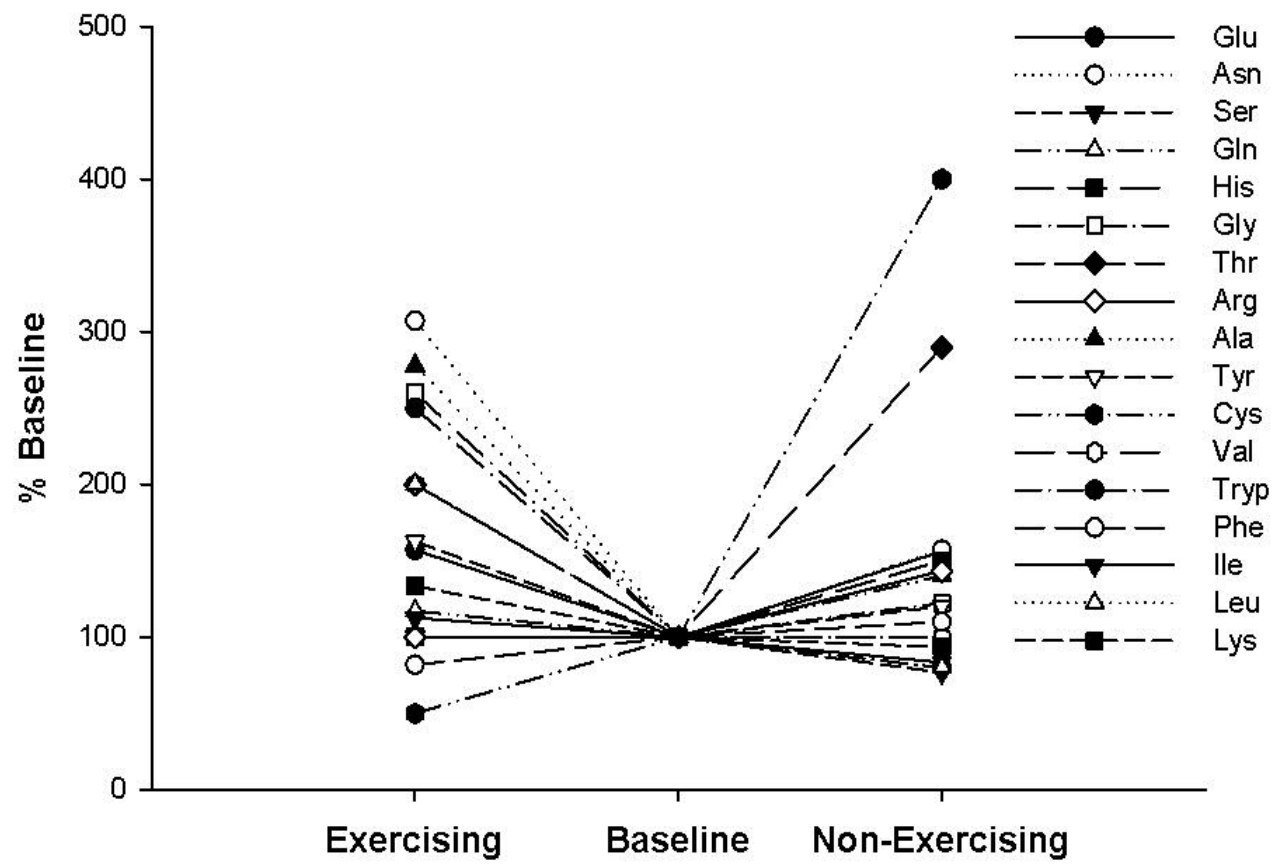


Figure2

Ala

Thr

Leu

Val
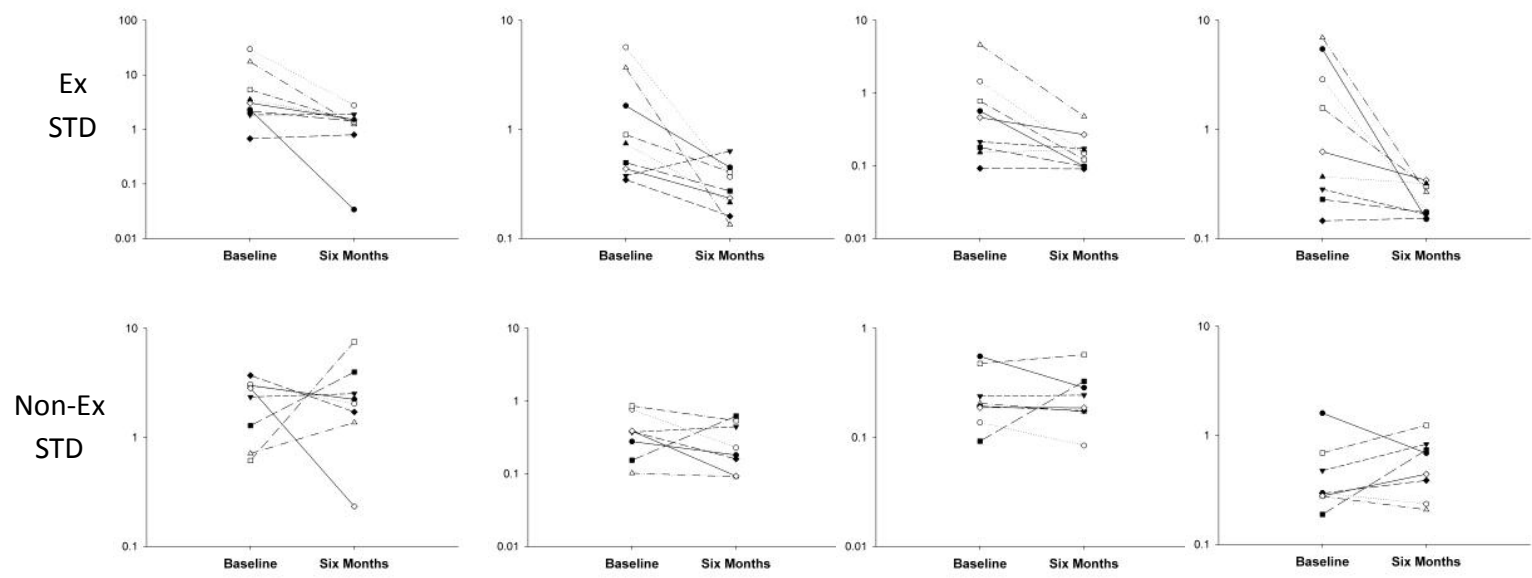
Figure 3a

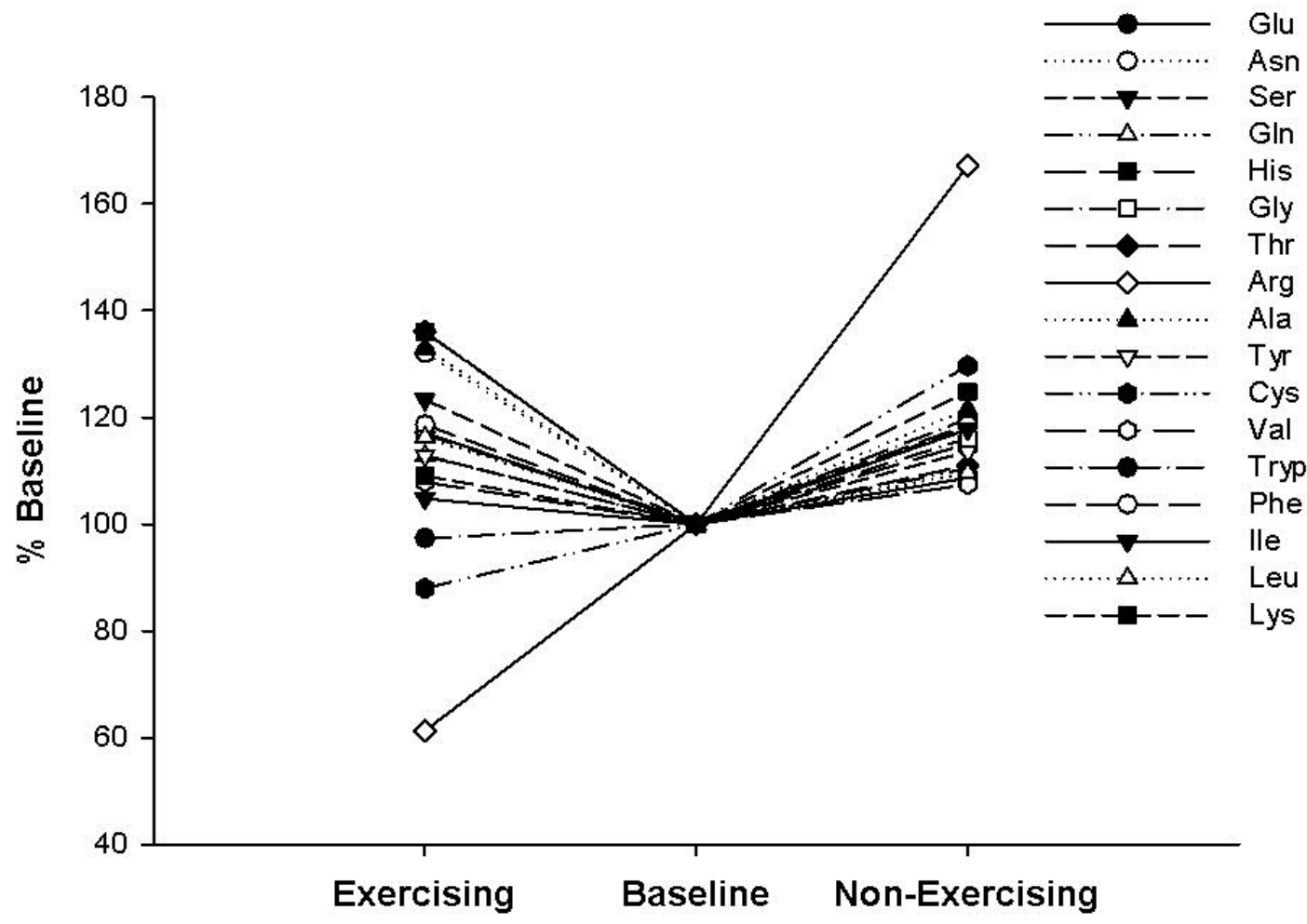

Figure $3 b$

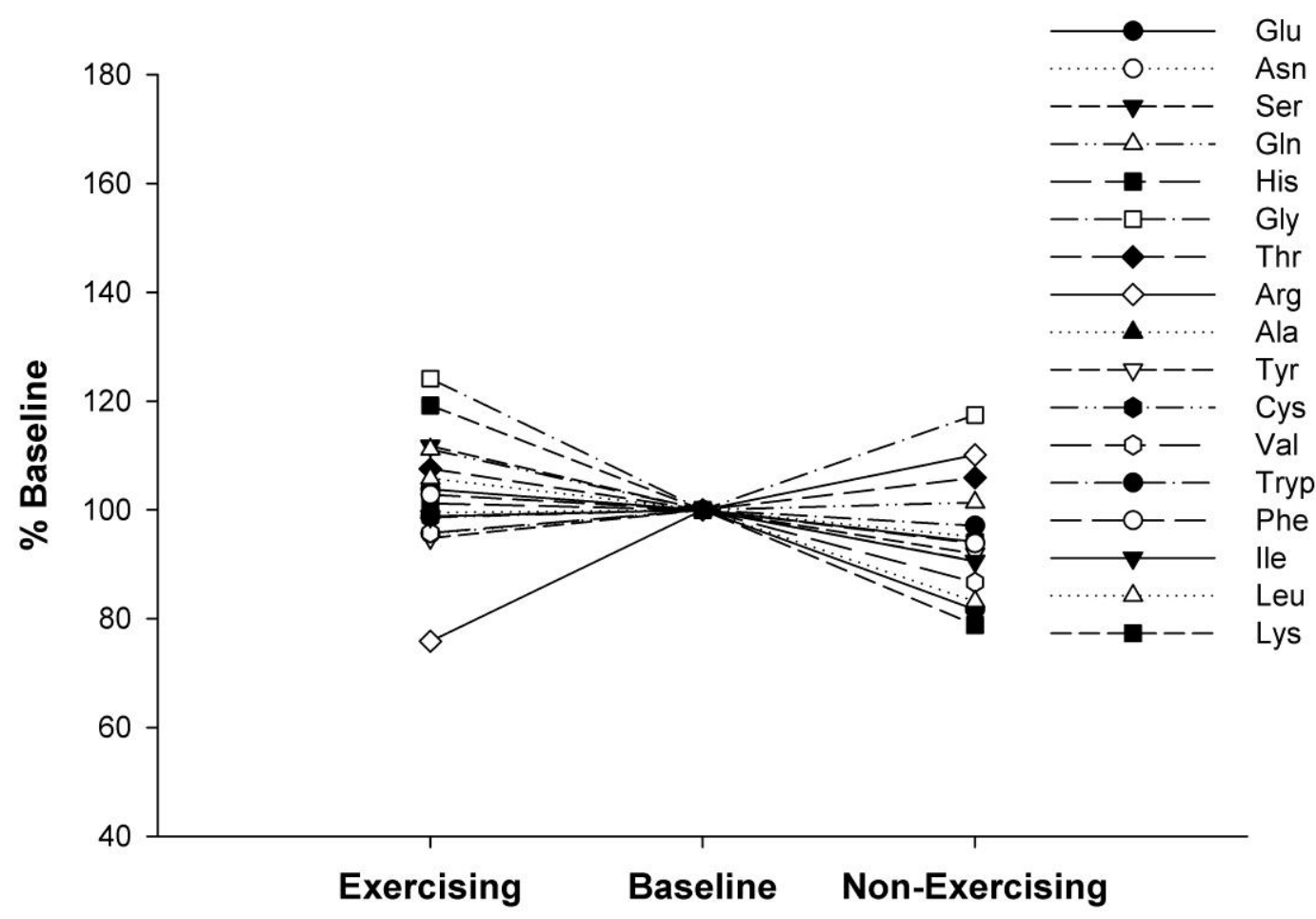


Figure 4a

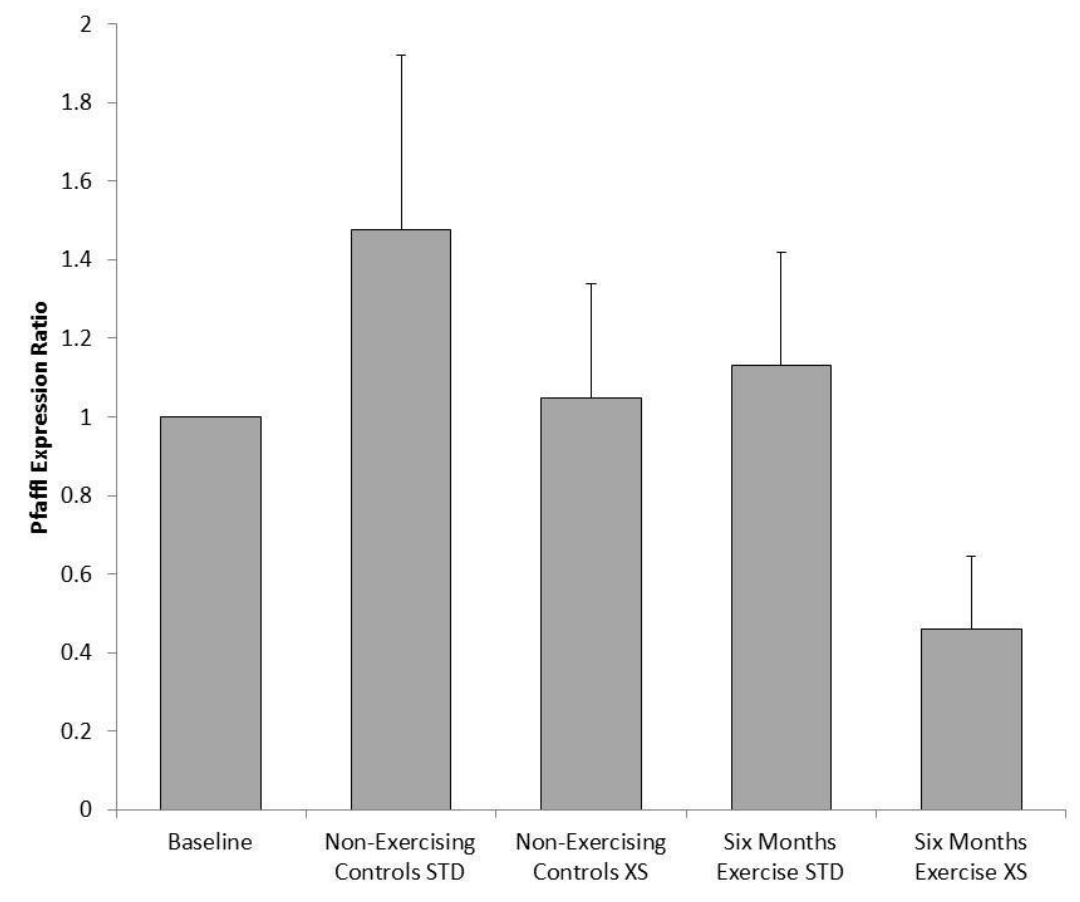

Figure 4b

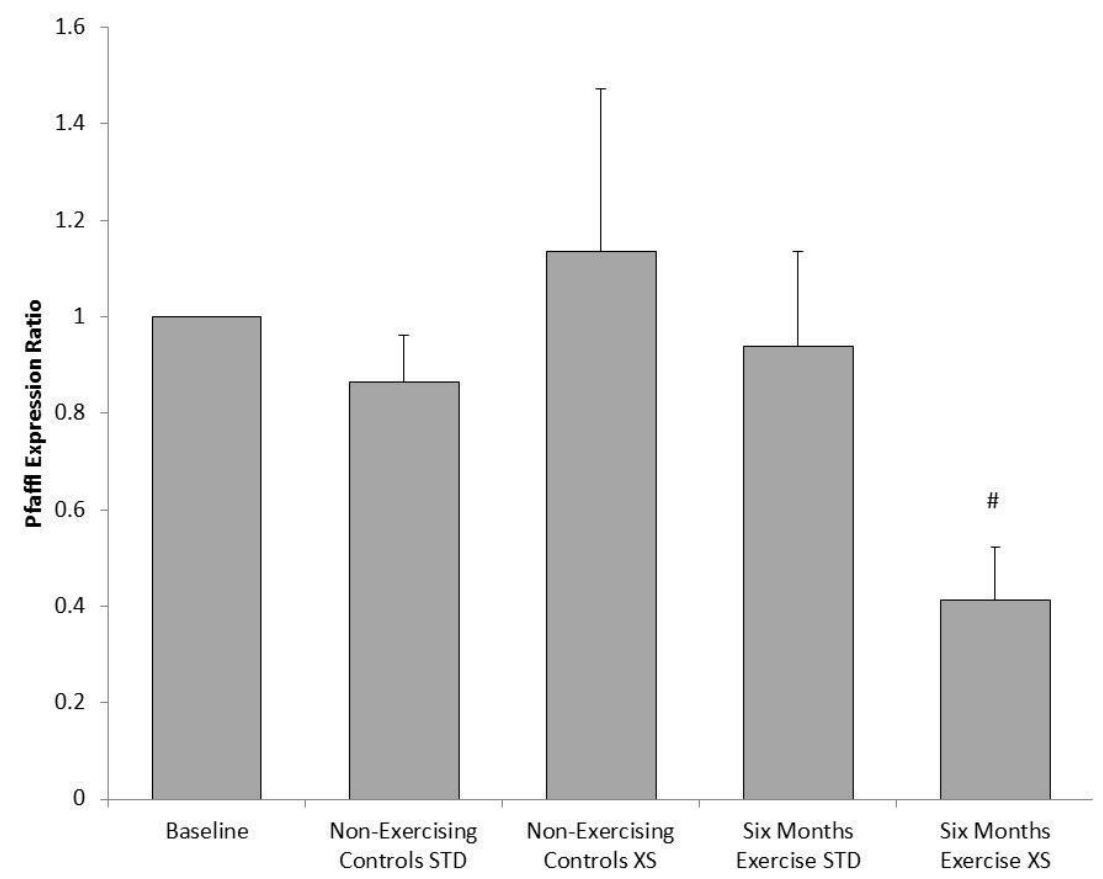


Figure 5

(a)

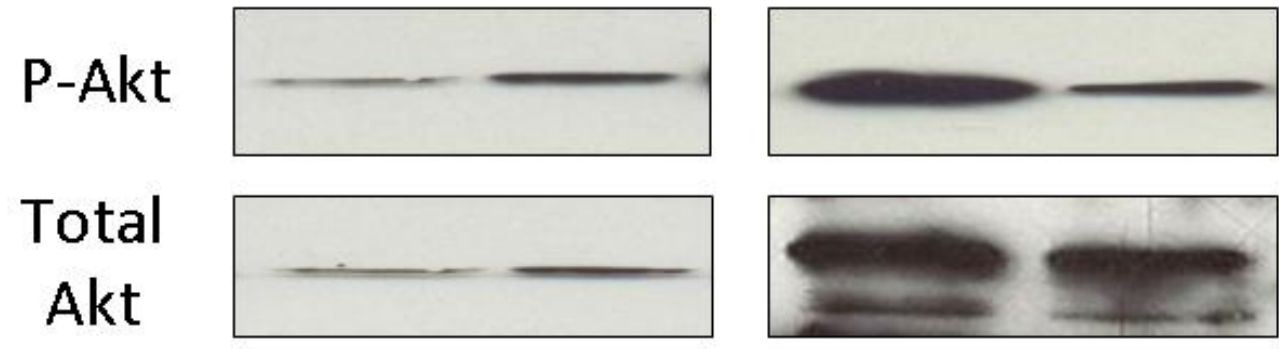

(b)

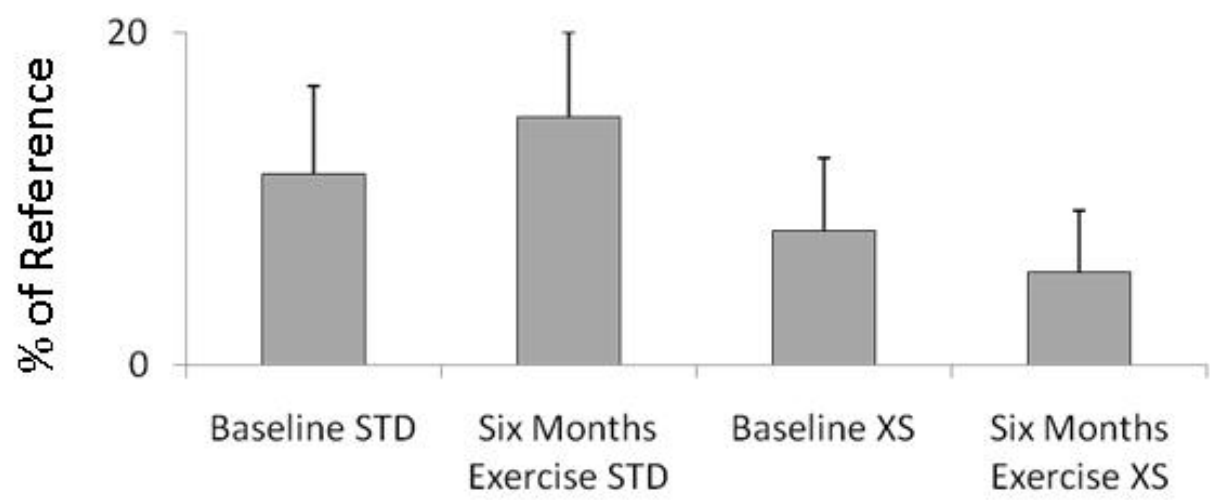

(c)
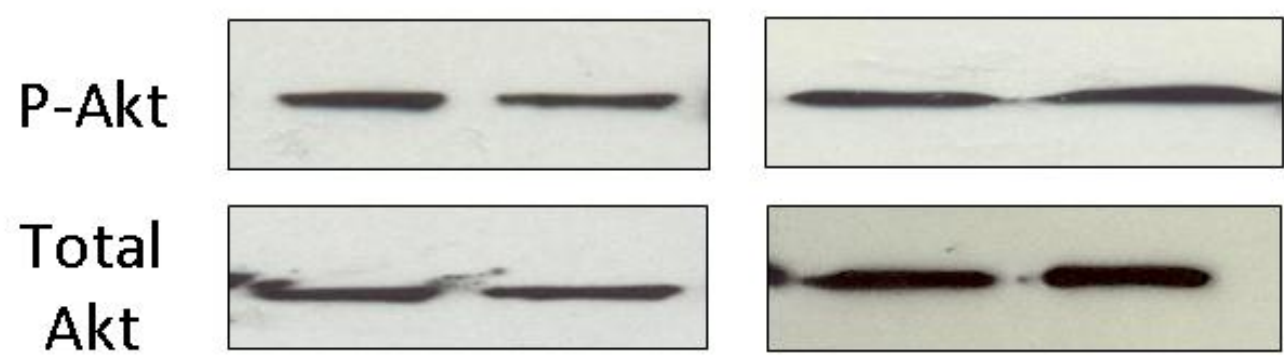

(d)

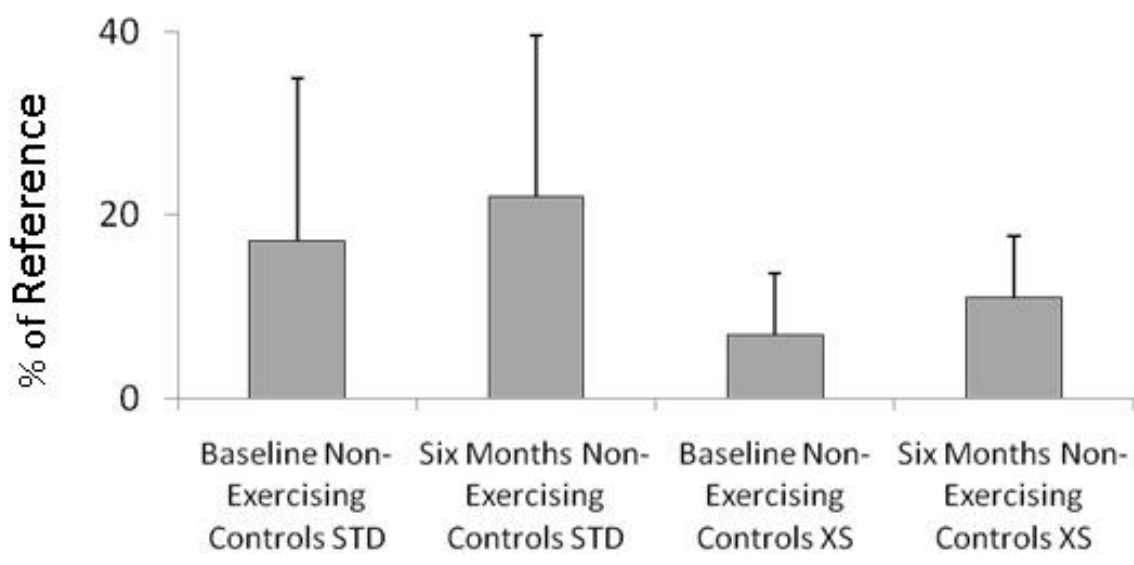


Figure 6

(a)
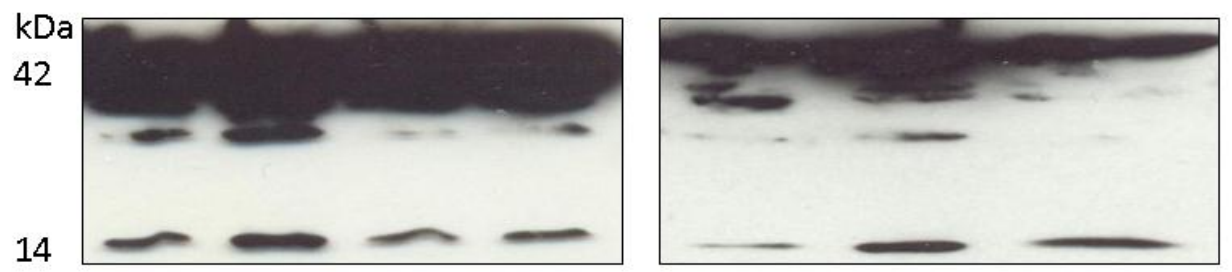

(d)

(b)

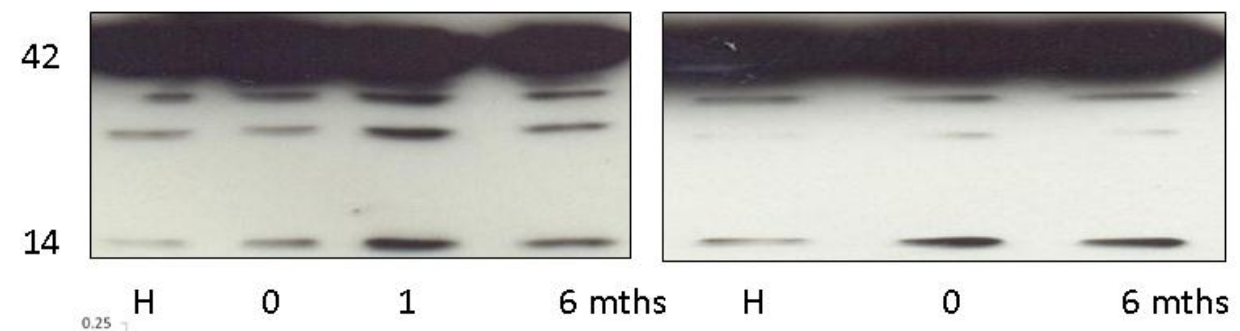

(e)

(c)
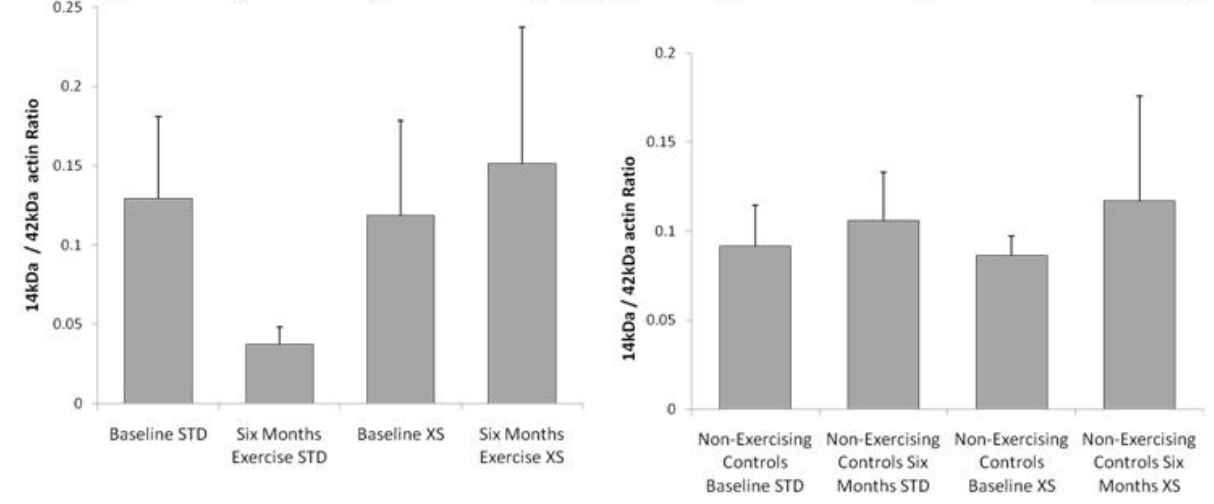

(f) 


\section{References}

Asola MR, Virtanen KA, Peltoniemi P et al (2001) Amino acid transport into skeletal muscle is impaired in chronic renal failure. Journal of the American Society of Nephrology : JASN 12:64A

Bailey JL, Zheng B, Hu Z, Price SR, Mitch WE (2006) Chronic kidney disease causes defects in signaling through the insulin receptor substrate/phosphatidylinositol 3-kinase/Akt pathway: implications for muscle atrophy. J Am Soc Nephrol 17:1388-1394. doi:10.1681/ASN.2004100842

Baird FE, Bett KJ, MacLean C, Tee AR, Hundal HS, Taylor PM (2009) Tertiary active transport of amino acids reconstituted by coexpression of System $A$ and $L$ transporters in Xenopus oocytes. Am J Physiol Endocrinol Metab 297:E822-9. doi:10.1152/ajpendo.00330.2009

Baird FE, Pinilla-Tenas JJ, Ogilvie WL, Ganapathy V, Hundal HS, Taylor PM (2006) Evidence for allosteric regulation of $\mathrm{pH}$-sensitive System A (SNAT2) and System N (SNAT5) amino acid transporter activity involving a conserved histidine residue. Biochem J 397:369-375. doi:10.1042/BJ20060026

Bergstrom J, Alvestrand A, Furst P (1990) Plasma and muscle free amino acids in maintenance hemodialysis patients without protein malnutrition. Kidney Int 38:108-114

Biolo G, Tipton KD, Klein S, Wolfe RR (1997) An abundant supply of amino acids enhances the metabolic effect of exercise on muscle protein. Am J Physiol 273:E122-9

Bodine SC, Stitt TN, Gonzalez M et al (2001a) Akt/mTOR pathway is a crucial regulator of skeletal muscle hypertrophy and can prevent muscle atrophy in vivo. Nat Cell Biol 3:1014-1019. doi:10.1038/ncb1101-1014

Borg GA (1982) Psychophysical bases of perceived exertion. Med Sci Sports Exerc 14:377-381

Cheema B, Abas H, Smith B et al (2007a) Randomized controlled trial of intradialytic resistance training to target muscle wasting in ESRD: the Progressive Exercise for Anabolism in Kidney Disease (PEAK) study. Am J Kidney Dis 50:574-584. doi:10.1053/j.ajkd.2007.07.005

Cheema B, Abas H, Smith B et al (2007b) Progressive exercise for anabolism in kidney disease (PEAK): a randomized, controlled trial of resistance training during hemodialysis. J Am Soc Nephrol 18:1594-1601. doi:10.1681/ASN.2006121329

Diesel W, Noakes TD, Swanepoel C, Lambert M (1990) Isokinetic muscle strength predicts maximum exercise tolerance in renal patients on chronic hemodialysis. Am J Kidney Dis 16:109-114

Dreyer HC, Drummond MJ, Pennings B et al (2008) Leucine-enriched essential amino acid and carbohydrate ingestion following resistance exercise enhances mTOR signaling and protein synthesis in human muscle. Am J Physiol Endocrinol Metab 294:E392-400. doi:10.1152/ajpendo.00582.2007

Du J, Wang X, Miereles C et al (2004) Activation of caspase-3 is an initial step triggering accelerated muscle proteolysis in catabolic conditions. J Clin Invest 113:115-123. doi:10.1172/JCl18330

Durozard D, Pimmel P, Baretto S et al (1993) 31P NMR spectroscopy investigation of muscle metabolism in hemodialysis patients. Kidney Int 43:885-892

Elia M, Carter A, Bacon S, Winearls CG, Smith R (1981) Clinical usefulness of urinary 3methylhistidine excretion in indicating muscle protein breakdown. Br Med J (Clin Res Ed) 282:351354

Evans K, Nasim Z, Brown J et al (2008) Inhibition of SNAT2 by metabolic acidosis enhances proteolysis in skeletal muscle. J Am Soc Nephrol 19:2119-2129. doi:10.1681/ASN.2007101108 
Evans K, Nasim Z, Brown J et al (2007) Acidosis-sensing glutamine pump SNAT2 determines amino acid levels and mammalian target of rapamycin signalling to protein synthesis in L6 muscle cells. $\mathrm{J}$ Am Soc Nephrol 18:1426-1436. doi:10.1681/ASN.2006091014

Franch HA, Raissi S, Wang X, Zheng B, Bailey JL, Price SR (2004) Acidosis impairs insulin receptor substrate-1-associated phosphoinositide 3-kinase signaling in muscle cells: consequences on proteolysis. Am J Physiol Renal Physiol 287:F700-6. doi:10.1152/ajprenal.00440.2003

Goldberg AP, Geltman EM, Gavin JR,3rd et al (1986) Exercise training reduces coronary risk and effectively rehabilitates hemodialysis patients. Nephron 42:311-316

Goldberg AP, Geltman EM, Hagberg JM et al (1983) Therapeutic benefits of exercise training for hemodialysis patients. Kidney Int Suppl 16:S303-9

Greenhaff PL, Gleeson M, Maughan RJ (1987) The effects of dietary manipulation on blood acid-base status and the performance of high intensity exercise. Eur J Appl Physiol Occup Physiol 56:331-337

Hyde R, Taylor PM, Hundal HS (2003) Amino acid transporters: roles in amino acid sensing and signalling in animal cells. Biochem J 373:1-18

Johansen KL (2007) Exercise in the end-stage renal disease population. J Am Soc Nephrol 18:18451854. doi:10.1681/ASN.2007010009

Johansen KL, Painter PL, Sakkas GK, Gordon P, Doyle J, Shubert T (2006) Effects of resistance exercise training and nandrolone decanoate on body composition and muscle function among patients who receive hemodialysis: A randomized, controlled trial. J Am Soc Nephrol 17:2307-2314. doi:10.1681/ASN.2006010034

Jones NL, Sutton JR, Taylor R, Toews CJ (1977) Effect of pH on cardiorespiratory and metabolic responses to exercise. J Appl Physiol 43:959-964

Kaizu Y, Ohkawa S, Odamaki M et al (2003) Association between inflammatory mediators and muscle mass in long-term hemodialysis patients. Am J Kidney Dis 42:295-302

Karlsson HK, Nilsson PA, Nilsson J, Chibalin AV, Zierath JR, Blomstrand E (2004) Branched-chain amino acids increase p70S6k phosphorylation in human skeletal muscle after resistance exercise. Am J Physiol Endocrinol Metab 287:E1-7. doi:10.1152/ajpendo.00430.2003

Kemp GJ, Crowe AV, Anijeet HK et al (2004) Abnormal mitochondrial function and muscle wasting, but normal contractile efficiency, in haemodialysed patients studied non-invasively in vivo. Nephrol Dial Transplant 19:1520-1527. doi:10.1093/ndt/gfh189

Kopple JD, Wang $\mathrm{H}$, Casaburi $\mathrm{R}$ et al (2007) Exercise in maintenance hemodialysis patients induces transcriptional changes in genes favoring anabolic muscle. J Am Soc Nephrol 18:2975-2986. doi:10.1681/ASN.2006070794

Kosmadakis GC, John SG, Clapp EL et al (2011) Benefits of regular walking exercise in advanced pre-dialysis chronic kidney disease. Nephrol Dial Transplant . doi:10.1093/ndt/gfr364

Kosmadakis GC, Bevington A, Smith AC et al (2010) Physical Exercise in Patients with Severe Kidney Disease. Nephron Clin Pract 115:c7-c16. doi:10.1159/000286344

Kouidi E, Grekas D, Deligiannis A, Tourkantonis A (2004) Outcomes of long-term exercise training in dialysis patients: comparison of two training programs. Clin Nephrol 61 Suppl 1:S31-8

Kovacic V, Roguljic L, Kovacic V (2003) Metabolic acidosis of chronically hemodialyzed patients. Am J Nephrol 23:158-164. doi:10.1159/000070205 
Lecker SH, Goldberg AL, Mitch WE (2006) Protein degradation by the ubiquitin-proteasome pathway in normal and disease states. J Am Soc Nephrol 17:1807-1819. doi:10.1681/ASN.2006010083

Lofberg E, Wernerman J, Anderstam B, Bergstrom J (1997) Correction of acidosis in dialysis patients increases branched-chain and total essential amino acid levels in muscle. Clin Nephrol 48:230-237

Mackenzie B, Erickson JD (2004) Sodium-coupled neutral amino acid (System N/A) transporters of the SLC38 gene family. Pflugers Arch 447:784-795. doi:10.1007/s00424-003-1117-9

MacRae HS, Dennis SC, Bosch AN, Noakes TD (1992) Effects of training on lactate production and removal during progressive exercise in humans. J Appl Physiol 72:1649-1656

Majchrzak KM, Pupim LB, Flakoll PJ, Ikizler TA (2008) Resistance exercise augments the acute anabolic effects of intradialytic oral nutritional supplementation. Nephrol Dial Transplant 23:13621369. doi:10.1093/ndt/gfm773

Matthews DE (2005) Observations of branched-chain amino acid administration in humans. J Nutr 135:1580S-4S

Mitch WE (2006) Metabolic and clinical consequences of metabolic acidosis. J Nephrol 19 Suppl 9:S70-5

Movilli E, Viola BF, Camerini C, Mazzola G, Cancarini GC (2009) Correction of metabolic acidosis on serum albumin and protein catabolism in hemodialysis patients. J Ren Nutr 19:172-177. doi:10.1053/j.jrn.2008.08.012

Nader GA (2006) Concurrent strength and endurance training: from molecules to man. Med Sci Sports Exerc 38:1965-1970. doi:10.1249/01.mss.0000233795.39282.33

Nicklin P, Bergman P, Zhang B et al (2009) Bidirectional transport of amino acids regulates mTOR and autophagy. Cell 136:521-534. doi:10.1016/j.cell.2008.11.044

Painter P (2005) Physical functioning in end-stage renal disease patients: update 2005. Hemodial Int 9:218-235. doi:10.1111/j.1492-7535.2005.01136.x

Painter P, Carlson L, Carey S, Paul SM, Myll J (2000) Physical functioning and health-related qualityof-life changes with exercise training in hemodialysis patients. Am J Kidney Dis 35:482-492

Painter P, Moore GE (1994) The impact of recombinant human erythropoietin on exercise capacity in hemodialysis patients. Adv Ren Replace Ther 1:55-65

Painter PL, Hector L, Ray K et al (2002) A randomized trial of exercise training after renal transplantation. Transplantation 74:42-48

Pfaffl MW (2001) A new mathematical model for relative quantification in real-time RT-PCR. Nucleic Acids Res 29:e45

Phillips SM, Tipton KD, Aarsland A, Wolf SE, Wolfe RR (1997) Mixed muscle protein synthesis and breakdown after resistance exercise in humans. Am J Physiol 273:E99-107

Proud CG (2004) mTOR-mediated regulation of translation factors by amino acids. Biochem Biophys Res Commun 313:429-436

Reaich D, Channon SM, Scrimgeour CM, Daley SE, Wilkinson R, Goodship TH (1993) Correction of acidosis in humans with CRF decreases protein degradation and amino acid oxidation. Am J Physiol 265:E230-5 
Stein A, Moorhouse J, lles-Smith $\mathrm{H}$ et al (1997) Role of an improvement in acid-base status and nutrition in CAPD patients. Kidney Int 52:1089-1095

Stitt TN, Drujan D, Clarke BA et al (2004) The IGF-1/PI3K/Akt pathway prevents expression of muscle atrophy-induced ubiquitin ligases by inhibiting FOXO transcription factors. Mol Cell 14:395-403

Szeto CC, Wong TY, Chow KM, Leung CB, Li PK (2003) Oral sodium bicarbonate for the treatment of metabolic acidosis in peritoneal dialysis patients: a randomized placebo-control trial. J Am Soc Nephrol 14:2119-2126

Tawney KW, Tawney PJ, Kovach J (2003) Disablement and rehabilitation in end-stage renal disease. Semin Dial 16:447-452

Wang XH, Du J, Klein JD, Bailey JL, Mitch WE (2009) Exercise ameliorates chronic kidney diseaseinduced defects in muscle protein metabolism and progenitor cell function. Kidney Int 76:751-759. doi:10.1038/ki.2009.260

Workeneh BT, Rondon-Berrios H, Zhang L et al (2006) Development of a diagnostic method for detecting increased muscle protein degradation in patients with catabolic conditions. J Am Soc Nephrol 17:3233-3239. doi:10.1681/ASN.2006020131

Zhang Z, Zander CB, Grewer C (2011) The C-terminal domain of the neutral amino acid transporter SNAT2 regulates transport activity through voltage-dependent processes. Biochem J 434:287-296. doi:10.1042/BJ20100507 